\title{
Organización de la protección social en España: problemas y políticas
}

\section{Jesús M. de Miguel * y Xavier Escandell **}

Durante las últimas décadas se debate en Europa la relación entre recursos de servicios sociales y sanitarios, dentro de un marco general de descentralización de la gestión pública. Se pone de moda también la complementariedad de recursos públicos y privados en el ancho campo de la protección social. En el caso de España es una sorpresa que el desarrollo económico coexiste con amplios niveles de desigualdad social. Durante la segunda mitad del siglo XX se cree a pies juntillas que el desarollo económico va a eliminar muchos de los problemas sociales previos: pobreza, prostitución, infancia abandonada 0 maltratada, alcoholismo, chabolismo, delincuencia, violencia, etc. La realidad es que ninguno de esos fenómenos - supuestamente de sociedades tradicionales y poco desarrolladas- desaparece. A veces se transforman... pero permanecen e incluso se -incrementan. A pesar de la creciente tolerancia de la sociedad española la marginación social sigue existiendo. Ya no se habla de desviación social, ni siquiera de marginación, sino directamente de exclusión social (que es la terminología de moda) refiriéndose a personas fuera de la sociedad, que no pertenecen a la estructura social. En otra terminología se utiliza el término underclass. Algunos de esos problemas sociales antiguos, de antes de la Guerra Civil, se transforman conformándose como la nueva pobreza, nueva delincuencia, nuevas dependencias que representan la herencia para el siglo XXI. Los problemas sociales aumentan a pesar de la crisis económica, o quizás a causa de la crisis, que se inicia a partir de 1973. En siete años (1986-1993) servicios sociales es un sector que casi duplica el personal -con un incremento del 97\% - en un ambiente de contención drástica de empleo que en números absolutos no aumenta más del $7 \%$ en ese mismo período. El objetivo es dar servicios sociales a la población necesitada, es decir, a los grupos de población con pro- blemas de precariedad y de exclusión, y sobre todo con la combinación de ambos factores. La teoría que cubre este proceso es la de axternalidades. La sociedad contemporánea crea problemas que no logra resolver, externalidades que se tratan de resolver con otras organizaciones. Para ello el Estado deja paso libre a la participación de instituciones privadas (como ONG) y voluntariado. Pero no cuestiona la estructura social, ni los procesos de desigualdad social. Tan sólo se diseña un sistema extenso, público, descentralizado pero coordinado nacionalmente, de servicios sociales para toda la población necesitada. Se trata incluso de extenderlo al resto de la población, como lo están el sector sanitario o el educativo***.

\section{Servicios sociales como última estrategia}

Los servicios sociales pueden ser considerados desde dos perspectivas distintas: como un sistema de caridad para las personas necesitadas y en ese sentido como realización básica del moderno Estado de Bienestar; o bien, como un sistema para reducir la presión social que puede demandar una reforma drástica de la sociedad actual y de la estructura social desigual que mantiene. En el trasfondo está la preocupación de que altas tasas de desarrollo y de desigualdad social pueden coexistir durante años. La población más afectada reúne dos factores: precariedad y exclusión. Precariedad se entiende fundamentalmente como pobreza, con sus múltiples dimensiones. El con- 
cepto de exclusión social es heredero del anterior de marginación social, que a su vez proviene del de desviación social. Se refiere sin duda a la misma población, pero el concepto acentúa el hecho de que la persona se desvía (voluntariamente?), es marginada por la sociedad, o incluso que es excluida del sistema social dominante. Se discuten los diversos conceptos de pobreza, y sobre todo los llamados umbrales de pobreza, tendentes a definiciones operativas como menos del 50\% de la mitad de los ingresos familiares medios.

Es un área mal definida, con contornos y márgenes difusos. aServicios sociales es un cajón de sastre de problemas sociales que van cambiando según evoluciona la sociedad y se producen nuevas externalidades. No hay una lista clara ni definitiva de situaciones o grupos sociales a los que aplicar los servicios sociales. Lo dominante es hablar de aservicios sociales" (desde una supuesta posición progresista) o de aacción social. (desde una posición conservadora). En ambas se distingue - sin mucha convicción ni claridad- entre servicios primarios y servicios especializados. Los primarios se denominan de varias otras formas: básicos, comunitarios, generales, de atención primaria, de base. Hay más unanimidad en la definición de aespecializados . El concepto originario de servicios sociales y de acción social es el de asistencia social ${ }^{4}$.

Tampoco hay acuerdo sobre qué servicios se deben realmente incluir en ese cajón de sastre de servicios sociales. Según las clasificaciones hay servicios que dependen de diversos grupos de edad: infancia (adopción, guarderías, niñez maltratada), juventud (con problemas), vejez (tercera edad, inválidos/as). Otros grupos sociales se incluyen dentro de servicios sociales debido a factores adscriptivos como género (mujer, mujeres maltratadas), o minorías étnicas. Ciertos grupos están incluidos por sus necesidades especiales. minusválidos, toxicómanos, delincuentes. Otros lo son por su status legal: reclusos, refugiados, apátridas. Incluso hay personas que se incluyen por su historia personal (inmigrantes) o por su ocupación (prostitutas, chaperos). En todos estos grupos se propone una situación específica de "problemas" que son definidos por la propia agencia que se encarga de solucionar luego esos problemas. La categoría siempre incluida en todas las clasificaciones es la de pobres. Se entiende "pobre" como persona que le falta lo necesario para vivir; pero los informes utilizan además categorías como la de transeúnte, vagabundo, mendigo, o la clasificación especial de «pobre de solemnidad. Otras veces se utilizan las de menesteroso, indigente y desamparado.

Se pueden definir tres interpretaciones sobre la organización de servicios sociales en España. La primera interpretación es que los servicios sociales son parte de una estructura básica del Estado de Bienestar. Una sociedad desarrollada tiene la responsabilidad de cubrir las necesidades fundamentales de la población, entre las que están un conjunto, extenso y variado, de acciones sociales que incluye todo tipo de servicios sociales. No es pues un elemento extraño, ni marginal, sino usual en ese Estado de Bienestar. Se tiende a que sea un sector fundamentalmente público, sobre el que sólo se permite alguna acción privada puntual o especializada siempre que sea sin ánimo de lucro y subsidiaria. Se admite que el Estado de Bienestar está en crisis, y que cada vez hay relativamente menos presupuesto en el sector público para estas tareas de servicios sociales, pero no se renuncia a ellas. Para cubrir mejor esos servicios públicos, y acercarse de forma más adecuada a las necesidades de la población, se tiende a descentralizar los servicios, situándolos a nivel municipal. La financiación sigue siendo estatal; el Estado y las Comunidades Autónomas controlan y coordinan esos servicios, y los municipios los realizan. El objetivo es crear una red pública extensa de servicios sociales. El objetivo final sería una red global de servicios sociales única, pública, y gratuita ${ }^{5}$. Se tiende también a la coordinación de los servicios sociales con los sanitarios, y en algunos proyectos incluso su unión en una red única ${ }^{6}$. Éste es aproximadamente el modelo diseñado por el Gobierno socialista (1982-1996) dominante en las últimas décadas del siglo XX.

Una segunda interpretación es que una sociedad moderna y desarrollada dentro de una economía globalizada no puede evitar el paro, la pobreza y la marginación ${ }^{7}$. El desarrollo económico actual suele venir acompañado de desigualdad social. Cada país puede optar por este desarrollo-con-desigualdad, o por no desarrollarse. En la teminología técnica los problemas sociales son extemalidades del propio sistema económico de desarrollo. La desigualdad y exclusión social se presentan en situaciones variadas como estrategias de problemas sin solución. Deben de ser atendidos con el menor coste posible para el sistema, principalmente para evitar males mayores, conflicto social, huelgas, malestar social, e inseguridad social. Se trata de evitar que la población general tenga problemas de relación, enfermedad (por contagio), vivienda, o comunitarios por culpa de esas externalidades. Pero la responsabilidad no es sólo del sector público. Es incluso posible hacer negocio de estos problemas sociales, y se admite que el sector privado —con y sin ánimo de lucro- se dedique a este sector. Suele ser también una responsabilidad, casi un monopolio, de una profesión concreta, la de Trabajo Social. Es una profesión que no alcanza el nivel de licenciatura, por lo tanto, con salarios medios, una capacidad limitada de dirección y de control de la gestión. Existen en su entorno otras ocupaciones diversas: educadores sociales, monitores, graduados sociales, animadores socioculturales, etc. Estos grupos profesionales (algunos de ellos con Colegios Profesionales activos) tienen lógicamente intereses en el diseño y realización de los servicios sociales ya que viven de ello. Suelen definir su propia demanda. La crítica es que los expertos/as definen los «problemas" por lo que sociológicamente los crean. 
Se considera que el paro, la pobreza y la exclusión social son costes inevitables del propio sistema actual de desarrollo y de producción. De forma esperanzada se sugiere que son costes temporales que se reducirán e incluso desaparecerán en el futuro. Mientras tanto debe minimizarse el conflicto al máximo y para ello es aceptable el apoyo del sector público a la existencia de varias redes públicas-y-privadas de asistencia social. Es posible que en el siglo XXI una sociedad más desarrollada logre que existan menos $\multimap$ incluso que desaparezcan - esas externalidades. Se argumenta que el desempleo, desigualdad y marginación sociales son costes inevitables pero no permanentes. Pero se está inseguro en torno a esta última afirmación. Por el momento no queda más remedio que atenderlas con el menor costo social y económico posible, controlándolas, etiquetándolas, generando, sin quererlo, ‘desviación secundaria. Se acepta, e incluso se favorece, que al mismo tiempo la responsabilidad sobre su control recaiga en modelos caritativos, por un lado, y profesionales, por el otro.

La tercera interpretación es importante en un país como España, con una extensa población que es religiosa (católica) y con numerosas instituciones dentro del sistema de poder que son directa o indirectamente católicas. Los servicios sociales pueden interpretarse como una forma modernizada de la antigua caridad y beneficencia. Se atiende a las personas pobres (necesitadas, indigentes, menesterosas, desamparadas, mendicantes, sin trabajo) y con problemas extremos de casi todos los tipos, como una forma de alcanzar la perfección, la comunicación cristiana de bienes (CCB), y la ayuda al prójimo como un deber religioso ${ }^{8}$. No se persigue la estatalización de los servicios sociales, ni que se convierta en una red pública exclusiva, sino que permanezca como un sector subsidiario, caritativo, de realizar la caridad cristiana con otros seres humanos. Se argumenta que ese modelo es más barato y que se basa en el trabajo de un voluntariado y en una red extensa de diócesis y parroquias. Se pretende que el Estado pague una parte sustancial de ese trabajo ${ }^{9}$, pero no que lo controle. En vez de especializarlo a través de una profesión dominante (Trabajo Social) y otras pseudoprofesiones, se adscribe a personal no especializado, a menudo con una adscripción religiosa (católica) clara, y a un voluntariado extenso que se confunde a veces con las/os fieles de la Iglesia católica ${ }^{10}$. Hay una cierta actitud fatalista que considera que la pobreza y la marginación social son parte irrenunciable de la naturaleza humana, y que siempre existirán. Incluso algunas personas entienden la pobreza como una forma de alcanzar objetivos personales de salvación eterna, tanto por parte del que da como del que recibe. De paso se aprovecha para realizar una crítica de la sociedad de consumo y capitalista. Hay una cierta tendencia a apropiarse de algunos sectores de esos servicios sociales (la pobreza, por ejemplo) casi como un monopolio de la caridad católica y de la beneficencia paraestatal. Se favorece un sistema sin ánimo de lucro, pero privado, supuestamente barato, que se solapa con una extensa red religiosa católica (el entramado de diócesis y parroquias), y con contenidos ideológicos propios. Parcialmente se utilizan los servicios de las profesiones dominantes pero no de forma exclusiva, y siempre que las decisiones sean tomadas por la red de caridad y no por la profesión como tal.

\section{Organización de la acción social}

Al final del siglo XX en el caso de España conviven las tres formas de organización de los servicios sociales. Dentro del sector público hay dos tendencias claras: a crear y a no-crear una red global de servicios sociales básicos (e incluso especializados) que se caracteriza por ser única, pública y gratuita. Estos dos modelos conviven con la tercera interpretación de caridadbeneficencia privada, mayoritariamente sin ánimo de lucro, con objetivos filantrópicos religiosos-católicos. Dentro de un cierto margen de maniobra cada Gobierno cambia un poco el rumbo del desarrollo de los servicios sociales en España, según su ideología política y social. En los años ochenta y noventa -hasta 1996- el modelo al que se tiende es una red pública extensa de servicios sociales, primarios y municipalizados. Con el Gobierno del PP (a partir de 1996) es posible se aplique otro modelo. Mientras tanto, la profesión dominante en ese sector (Trabajo Social) tiene cada vez un poder más definido y controla numerosos procesos de toma de decisión. Sus colegios profesionales tienen cada vez más poder. Esta profesión entra en conflicto con otras ocupaciones dentro del área de las ciencias sociales y sanitarias, por el reparto de puestos de dirección, coordinación, trabajo, salarios, presupuesto y equipamientos. El proceso de apropiación de un monopolio y lucha contra el intrusismo (objetivo típico de cualquier profesión) crea conflicto con los tres modelos de organización del Estado de Bienestar, de desarrollo/desigualdad, y de caridad, como una cuarta fuer$z a$ social que cada vez conviene tener más en cuenta en el análisis del sector de servicios sociales.

En España el sector de servicios sociales se organiza actualmente como un sistema mixto, es decir, de responsabilidad pública y privada. En el sector público hay tres instituciones diferentes: la asistencia social del Estado, los servicios sociales de la Seguridad Social y la beneficencia municipal. La asistencia social del Estado se concentra fundamentalmente en el Ministerio de Asuntos Sociales (MAS), que a partir de 1996 es parte del Ministerio de Trabajo (MiTAS) ${ }^{11}$. El MAS incluye el Plan Concertado de Prestaciones Básicas de Servicios Sociales en las Corporaciones Locales, el Plan de Igualdad de la Mujer, el Plan de 
Juventud, el Plan Gerontológico, etc. En otros Ministerios hay otras responsabilidades adicionales, sobre todo en el Ministerio de Sanidad con el Plan Nacional sobre Drogas, así como los servicios relacionados con el síndrome tóxico, sida, alcoholismo, deficiencias/discapacidades/minusvalías, maltrato físico, enfermedades crónicas, etc. Los servicios sociales de la Seguridad Social son varios, pero el más importante es el Inserso (Instituto Nacional de Servicios Sociales). La beneficencia municipal es partc del Plan Concertado (PCPBSSCL), coordinado por las Comunidades Autónomas, y a su vez por la Administración Central. Es financiado por los tres niveles.

Aparte hay un sector privado, que se entiende que es subsidiario del público, pero no siempre es así. La realidad es que existe un sector no lucrativo extenso, con varias macroorganizaciones como Cruz Roja Española, Cáritas Española, ONCE (Organización Nacional de Ciegos/as de España), y la "Obra Social" de las Cajas de Ahorros. Estas organizaciones tienen una importancia básica para entender los servicios sociales en España. Además, cada vez se acepta más la existencia de un sector privado lucrativo en servicios sociales, por ejemplo en residencias de ancianos/as.

El sistema es mixto, lo que en realidad lleva a que esté poco coordinado, y menos aún evaluado. Continuamente se habla de llegar a un sistema integrado aunque nunca se define claramente lo que supone exactamente eso de integradon. Suele expresar el objetivo de una coordinación total de los tres sectores (público, privado no lucrativo y privado for profit) a nivel nacional español. Otras veces se refiere a que los servicios sociales no se planifiquen sólo para los grupos sociales necesitados, sino para la población total.

Históricamente, el modelo evoluciona desde un sistema prevalente de beneficencia privada (en manos de órdenes religiosas y fundaciones) a una beneficencia pública a cargo de una profesión laica establecida con nivel universitario intermedio, que es Trabajo Social. Se vuelve a poner de moda la intervención de la beneficencia privada, ahora bajo la etiqueta de ONG, voluntariados y otros tipos de asociaciones. Los procesos de cambio son a veces de ida-y-vuelta, como el paso de beneficencia privada a pública, y vuelta otra vez a privada.

Pero el cambio más importante es el proceso de descentralización, que no es una característica única de España sino de la mayoría de los países europeos. La descentralización se entiende del Estado central a los municipios. El poder real lo tienen las 17 Comunidades Autónomas, aunque desde 1985 (según la Ley de Régimen Local) la atribución de responsabilidad es a los municipios, fundamentalmente a los mayores de veinte mil habitantes. Esta descentralización puede llevar a ciertos desequilibrios. La crítica de algunos sociólogos es clara: .Cabe preguntarse si la descentralización de los servicios sociales no es una vía de descompromiso estatal y, lo que es más importan- te, una forma de difuminar la visibilidad de los nuevos problemas sociales" (Rodríguez Cabrero, 1996: 371). Pero el proceso de cambio más importante es el paso de la responsabilidad familiar de esos estados de necesidad, y sobre todo del cuidado proveído por mujeres, a su institucionalización en una profesión concreta y en una organización compleja diseñada en forma de red.

Es curioso que sigue siendo una responsabilidad de mujeres. La profesión dominante, Trabajo Social, es mayoritariamente de mujeres. Los centros del sector público, del sector privado y del voluntariado están compuestos sobre todo por mujeres. No sólo se feminiza el cuidado, y la profesión cuidadora, sino que incluso se produce un proceso claro de feminización de la pobreza, en base a la multiplicación de familias monoparentales (en que la cabeza es una mujer). La población atendida por servicios sociales es crecientemente femenina (y niñas/os). Se produce un fenómeno de institucionalización, pero el tipo de capital humano sigue siendo el mismo.

Trabajo Social se configura como una profesión débil, que no alcanza el nivel de licenciatura (es una diplomatura), y que se enfrenta con un proceso de segmentación del trabajo. Por un lado, cada vez aparece más controlada por otras profesiones dominantes, y gradualmente las tareas más manuales son realizadas por otras personas con menos estudios. A pesar de esas dos tendencias opuestas, Trabajo Social sigue manteniendo un monopolio relativo de servicios sociales y, sobre todo, el control de la dirección y coordinación de la mayoría de los centros. La tendencia es hacia la disminución de ese poder.

Dentro del sector de servicios sociales el tema de discusión fundamental es el del empleo, y no el de la población o las personas atendidas. Hay datos sobre las personas que trabajan en servicios sociales, pero muy poco de sus clientes o de las personas atendidas. Éste es un sesgo evidente -e inexplicable- para cualquier investigador/a social que se aventure en ese sector. El desarrollo de los servicios sociales crea una plantilla de trabajadores/as que se incrementa a bastante más velocidad que el total del empleo, y que está compuesto sobre todo por población activa femenina. Su número aumenta incluso a más velocidad que el trabajo que realizan. A pesar de la crisis económica es un sector en expansión. Entre 1986 y 1993 el empleo en este sector aumenta un $97 \%$, aproximadamente un $10 \%$ anual ( $9 \%$ de varones, y $11 \%$ de mujeres), mientras que en esas mismas fechas el empleo total apenas crece un $7 \%$.

La expansión se debe a la acción controladora del Estado y a la oferta de trabajo de mujeres. Es un sector cada vez más público. En 1986 el sector público supone ya el 46\% del empleo del sector, pero asciende al $53 \%$ siete años después ${ }^{13}$. Se observa pues un proceso de feminización del empleo de servicios sociales. Siempre ha sido alto: en 1986 el $76 \%$ de las personas que trabajan en ese sector son mujeres, y en 1993 aumenta al 78\%. 
No crece tanto la participación femenina como podría suponerse (apenas un 3\% de incremento en siete años), pero es ya alta. Hay que tener en cuenta que en el empleo total en esos mismos años las mujeres pasan del $29 \%$ al $34 \%$. De los nuevos empleos en servicios sociales creados en el mismo período el $81 \%$ son cubiertos por mujeres.

Son empleos cada vez más asalariados, siguiendo también la tendencia del empleo general. En 1986 en servicios sociales el $89 \%$ son empleos asalariados, subiendo hasta el $95 \%$ en 1993 . Este dato sugiere que son empleos relativamente precarios. El empleo temporal en el sector, de servicios sociales aumenta en esos siete años del $17 \%$ al $38 \%$. La temporalidad en el caso de las mujeres aumenta del $15 \%$ al $41 \%$ en las mismas fechas. La temporalidad proviene en parte del propio proceso de descentralización. Los municipios, con presupuestos anuales no asegurados, se ven obligados a establecer contratos provisionales ${ }^{14}$.

Es un empleo cada vez más dicotómico. Cada vez está compuesto de personas más jóvenes y más viejas. El número de personas menores de 25 años pasa del $9 \%$ al $12 \%$, pero a su vez las personas de más de 64 años aumentan del $7 \%$ al $10 \%$ en esos siete años. Esa tendencia dicotómica se puede apreciar también en su nivel de estudios. Cada vez hay más personas empleadas con estudios universitarios, y a su vez más personas sin estudios. La proporción de personas con título universitario pasa en siete años del $50 \%$ al $55 \%$. Las personas sin estudios también se incrementan en número, del $8 \%$ al $10 \%$.

Es, pues, un sector en expansión -a pesar o a causa de la crisis económica, como se prefiera- cada vez más público, femenino, asalariado, precario, y dicotómico. Está compuesto de empleos mal pagados, con una profesión dominante con status limitado, y con poca capacidad de control del proceso global de expansión. Las transformaciones que se pueden producir en el siglo XXI son grandes. El tema del empleo en el sector de servicios sociales no es baladí, pues, dada la indefinición de los derechos individuales de la población, una parte apreciable de lo que se atiende en el sector de servicios sociales es definido por el propio profesional. La composición y características del personal es, pues, importante para el tipo de trabajo dentro del sector. Es una situación típica de círculo vicioso, de enorme interés para el análisis sociológico.

Los estados de necesidad de la población, o de grupos sociales (o personas) concretos, se pueden explicar desde la oferta o la demanda. El lado de la oferta está representado por los servicios sociales y sobre todo sus empleados/as; el lado de la demanda es la población pobre y necesitada, precaria y excluida. El sector entero es usualmente analizado -incluso por los sociólogos/as- desde la oferta. Así, parecen importar más los problemas de empleo del personal de las instituciones que las situaciones de necesidad de la población. Falta realmente una evaluación de los servicios y de la atención que la población recibe. No existe un buen análisis de las necesidades reales de la población. Falta además un estudio de los procesos de toma de decisión en servicios sociales. No hay datos suficientes para realizar esos estudios, y lo poco que se sabe a través de encuestas es de consistencia débil. Las encuestas tienden normalmente a no incluir a la población excluida que conforma los grupos fundamentales de los servicios sociales. Pobres de solemnidad, prostitutas, vagabundos, mujeres maltratadas, minusválidos, enfermos profundos, delincuentes, gitanos, reclusos, huérfanos, inmigrantes ilegales, toxicómanos, enfermos terminales, niños (de todos los tipos), apátridas, alcohólicos, personas hospitalizadas e internos en instituciones, etc., no suelen formar parte de las muestras de las encuestas. Cualquier información ofrecida a través de encuestas generales de la población debe ser pues aceptada con precaución.

El modelo español de servicios sociales -si es que puede hablarse de que existe un modelo- copia los sistemas extranjeros y sus transformaciones recientes ${ }^{15}$. Se adoptan sobre todo los modelos anglosajones y franceses. Dentro de España el proceso de descentralización lleva a que las Comunidades Autónomas innoven cada una por su lado, copiando a su vez modelos foráneos más o menos exitosos. Paradójicamente, las Comunidades Autónomas más avanzadas en España son las que no pertenecen al Plan Concertado (PCPBSSCL), y que tienen menos pobreza y exclusión: País Vasco y Navarra. Son territorios tradicionalmente con pocos pobres, en donde prosperan más los planes contra la pobreza. En zonas donde el desempleo y la pobreza son enormes (como Extremadura) los modelos aparecen menos desarrollados. Quizás es un problema de self fulfilling prophecy.

Los servicios sociales se definen con relación a los/as ciudadanos, es decir, población con derechos de ciudadanía. Así, cuando se habla de "minorías étnicas" no se refiere a inmigrantes ilegales sino más bien a gitanos/as. aLas previsiones legales reconocen como titulares del derecho a los servicios sociales a los ciudadanos españoles con residencia en la Comunidad Autónoma respectiva, así como a los transeúntes en la misma que tengan nacionalidad española. ${ }^{16}$. Un factor fundamental de necesidad suele ser precisamente el no tener la nacionalidad, y sobre todo el ser ilegal. Se requiere, pues, una redefinición de la población con derecho a ser atendida. El problema es más general: no hay una definición clara de derechos sobre la extensa variedad de servicios sociales que es posible llegar a ofrecer. Eso lleva a que sea el personal el que defina -desde el punto de vista de sus profesiones respectivas y de la ofertalos servicios que se prestan. Servicios sociales es un sector planificado desde la oferta y no desde la demanda.

La descentralización se considera como un proceso inteligente en el que las necesidades de las personas son mejor aten- 
didas desde una posición más cercana a la realidad, sobre todo a nivel municipal. Este enfoque recibe algunas críticas. El número de municipios es considerable en España; en 1991 hay 8.077 municipios. En el período intercensal 1981-1991 su número crece casi un $1 \%$. El $74 \%$ de los municipios españoles son menores de dos mil habitantes. No es posible mantener una responsabilidad real de servicios sociales con municipios tan pequeños. Hay ciertos problemas y necesidades de la población que se resuelven comunitaria o familiarmente, sin un proceso de intervención de profesionales. Sería conveniente que los municipios tuviesen un tamaño suficiente para resolver los servicios básicos a nivel del Ayuntamiento; pero eso supondría una reforma administrativa compleja que está todavía por realizar en España.

El sector de servicios sociales no acepta fácilmente la iniciativa privada, sobre todo si es con ánimo de lucro. Pero en otros sectores cada vez se acepta más la responsabilidad del sector privado, como en el sector sanitario o en educación privada que en España es tan importante. Es posible que en el siglo XXI la intervención privada en el sector de servicios sociales sea cada vez mayor, aunque también es posible que cada vez la responsabilidad pública sea gradualmente más importante. El sector público puede pagar servicios que son realizados por otras instituciones, incluso no-públicas. Es parte también de un proceso dicotómico. Como el sector está compuesto por servicios variados y distintos, cada uno puede tener una estructura diferente. No hay unanimidad sobre un modelo, ni se cree que tenga que existir. Por definición las externalidades son variadas, y la resolución de esas externalidades crea organizaciones que a su vez producen externalidades. Es un modelo de muñecas rusas, en que los problemas contienen a su vez otros problemas.

Una tendencia lógica - propuesta por ciertos grupos en el poder- es la unión y no sólo coordinación de los servicios sanitarios y sociales. Hay muchos aspectos solapables en áreas limítrofes como drogadicción, minusvalía, maltrato, alcoholismo, epidemias (colza y sida), población reclusa, pobreza profunda, malnutrición, vejez desasistida, senilidad, incluso delincuencia. -Conseguir una relación coherente entre los servicios sanitarios y los servicios sociales es [...] una de las asignaturas pendientes de la política social española ${ }^{17}$. No es fácil; existe una rivalidad clara entre profesiones: la profesión médica que domina el sector sanitario, y la profesión de trabajo social que domina todavía el sector de servicios sociales. Servicios sociales es un sector de empleo cada vez más segmentado, con licenciados/as que se desgajan de la profesión y ocupan puestos de direccióncoordinación; y personas sin estudios y voluntariado que ejercen labores de base. La profesión de trabajo social (antes denominada de asistente social) es similar a la de enfermería (que antes era ATS). Ambas tienen un nivel de diplomatura uni- versitaria. Pero en el caso de la Enfermería por encima existe una profesión dominante en el sector sanitario, mientras que Trabajo Social no tiene por encima una profesión dominante clara (o única) en servicios sociales. Ese lugar es ocupado por varias profesiones con nivel de licenciatura como economía 0 sociología. Por el momento, pues, la unión de ambos sectores parece un objetivo complicado de alcanzar, aunque los/as clientes - la población - saldría beneficiada.

El sector público de la Seguridad Social siempre ha cumplido en España una cierta función de servicios sociales, considerada antes como aasistencia social. Sus objetivos aparecen perfilados en la Ley de Bases de la Seguridad Social de 1963. El sector privado también se pone en marcha alrededor de esos años, generando dentro de la Iglesia Católica una redefinición de su trabajo de asistencia social y de beneficencia, a través de Cáritas Española y del Plan CCB ${ }^{18}$. En 1977 el Ministerio de Trabajo asume esa responsabilidad con la creación de una Dirección General que va cambiando de nombre: de Asistencia Social y Servicios Sociales, de Servicios Sociales, de Acción Social y de Asuntos Sociales. En pocos años se pasa pues del concepto de beneficencia privada (religiosa-católica fundamentalmente) a beneficencia priblica, luego a asistencia social, de ahí a servicios sociales y más modernamente a acción social. La marginación de la población, objeto de la acción social, se refleja en la marginación del propio área de estudio. Se reconoce así que aestamos ante unas actividades que ocupan posiciones marginales en nuestra cultura" ${ }^{19}$. Van cambiando con cierta frecuencia de nombre, de Dirección General, e incluso de Ministerio. La definición de las tareas y servicios es más constante pues se realiza desde el lado de la oferta y no de la demanda. La demanda es poco definible y desconocida, siendo un fenómeno típicamente iceberg.

En España la beneficencia no es un invento antiguo. La ley General de Beneficencia es de 1849. La concepción de esa ley perdura muchos años. La Guerra Civil de 1936-1939 transforma algunas de las instituciones de ese sector. Así, la organización llamada Auxilio de Invierno que se desarrolla en el bando franquista durante la guerra pasa luego a denominarse Auxilio Social $^{20}$. Es responsabilidad de la Sección Femenina de Falange Española. Luego, la dictadura franquista lo cristaliza en un sistema de ayudas económicas a la población en momentos de emergencia - Asistencia Social- y un área variada de Servicios Sociales como el SAP, Servicio de Asistencia a Pensionistas, y el SEREM, Servicio de Recuperación y Rehabilitación de Minusválidos/as Físicos y Psíquicos. Primero crea el Fondo Nacional de Asistencia Social (conocido como FONAS) en 1960, y luego el INAS Instituto Nacional de Asistencia Social en 1974. El concepto dominante en esos años deja de ser el de auxilio social. para pasar al de aasistencia social. Al igual que en sanidad se evoluciona de asistencia sanitaria a atención sanitaria, en servicios so- 
ciales se pasa de asistencia social a trabajo social. Los conceptos van variando, y con ellos los rótulos de las instituciones, la plantilla de personal y la intencionalidad política e ideológica.

Tras la muerte de Franco, es hacia final de los años setenta cuando el sector se institucionaliza de forma más moderna desde una Dirección General de Asistencia Social y Servicios Sociales (en 1977) dentro del Ministerio de Trabajo. El sector de servicios sociales es ya parte del sector de empleo y trabajo y no tanto del de orden público o Ministerio de la Gobemación (actualmente de Interior). Este cambio es importante, pues los grupos sociales marginados no se consideran ya como generadores de problemas sociales sino como victimas de esos problemas sociales. Se crea un año después el Instituto Nacional de Servicios Sociales (conocido como Inserso) en que se desarrollan programas para ancianos/as y para personas con minusvalía. Hacia 1982 se promulga la Ley de Integración Social de los Minusválidos (varones y mujeres) conocida como LISMI.

La Constitución de finales de 1978 es ambigua sobre el tema de los servicios sociales. Propone un proceso de descentralización de todo el sector hacia las 17 Comunidades Autónomas, que asumen así la competencia exclusiva de los servicios sociales. Se empiezan a observar diferencias regionales debidas a ese proceso de descentralización. Las Comunidades Autónomas más ricas plantean programas más avanzados y con una cobertura mayor. Incluso proponen soluciones más importantes como la renta o ingreso minimo de inserción ${ }^{21}$. Esta política de servicios sociales es más novedosa pues no sólo supone la intervención individual sino además programas de einserción. social y de desarrollo comunitario. Se desarrollan luego tres niveles de ayuda individual: de auxilio, de prevención y de rehabilitación; junto con un objetivo más general de cambio social y desarrollo comunitario en áreas socialmente problemáticas.

Los catorce años del Gobierno del PSOE, 1982-1996, suponen la institucionalización de un modelo público de servicios sociales divididos en básicos y especializados. Se tarda seis años en establecer una red pública de servicios sociales conocida como el Plan Concertado, con el nombre tan poco comercial de aPlan Concertado de Prestaciones Básicas de Servicios Sociales en las Corporaciones Locales. Se pone un énfasis especial en el nivel de atención primaria (básica, general) y a nivel municipal. Se entiende que los servicios especializados no sólo son caros sino que además tienden a marginar a la población ya marginada. La crítica al centralismo franquista produce una descentralización en los municipios, que algunos consideran como una erecentralización en las Comunidades Autónomass ${ }^{22}$.

¿Si los servicios sociales es un instrumento eficaz para disminuir las desigualdades sociales, por qué no utilizarlo para toda la población y no sólo para grupos sociales precarios y excluidos? La nueva idea es crear un sistema público similar al sanitario o al educativo, con una red que incluya la población general y todo el territorio nacional. Este objetivo se propone bajo la forma de un .Plan Concertado, que en principio agrupa los esfuerzos que ya están realizando todos los sectores y niveles de la Administración Pública: central, autonómica y local. Este objetivo se intenta lograr sin haber realmente evaluado la efectividad de los servicios sociales públicos que se están realizando, ni tampoco medir su impacto para lograr una mayor igualdad social. El beneficio se da por supuesto.

A partir de 1988 se pone en marcha el Plan Concertado; al principio de forma lenta pero posteriormente acelerada y progresiva. El sistema del Plan Concertado gira en torno a los llamados "Centros de Servicios Sociales" que se crean en las 15 Comunidades Autónomas del Plan (no incluye Navarra ni el País Vasco). Estos Centros están compuestos fundamentalmente de trabajadores sociales con una cierta ayuda administrativa, dirigidos por ellas mismas (la mayoría de los trabajadores sociales son mujeres), y a veces - de forma creciente- por licenciados/as de otras profesiones. Hay mucha ayuda a domicilio que se realiza por personal con pocos estudios e incluso por voluntarios/as. El objetivo son las prestaciones básicas de orientación, ayuda a domicilio, acogida en situaciones extremas y ayuda a personas que no tienen un lugar fijo para vivir. Otro objetivo importante es la prevención e inserción social que se define como: antervenciones realizadas por equipos profesionales, dirigidos a personas o colectivos en situaciones de riesgo o marginación social, con el objeto de prevenir marginaciones sociales y, en su caso, lograr su reinserción familiar y social ${ }^{23}$. Aunque la terminología es típicamente de servicios sociales, la estructura organizativa que se propone recuerda bastante al modelo del Sistema Nacional de Salud. El objetivo es dar una cobertura mínima - parecida en todas las Comunidades Autónomas- para todos los españoles/as.

El Plan Concertado - al igual que el Sistema Nacional de Salud - no supone la creación ex novo de una estructura nueva de servicios sociales, sino que los servicios sociales que ya existen se van incorporando al Plan. Así se explica el desarrollo súbito en pocos años. El Plan Concertado es pues un acuerdo entre municipios, Comunidades Autónomas (15), y la Administración Central (fundamentalmente el MAS, y luego el MiTAS). En una segunda etapa es más creadora, y se expande gracias a la ayuda a domicilio. También se produce una cierta cristalización, observable en una tendencia al funcionariado, pero problemática debido a la situación presupuestaria precaria de los Ayuntamientos.

El Plan Concertado supone la institucionalización de la profesión de Trabajo Social dentro de una organización en forma de red, con una estructura laica y pública. La proporción de licenciados/as entre el personal es inicialmente menor del 5\%, pero se incrementa año a año. Cada vez la organización aparece más dominada por personal que no son trabajadores socia- 
les, que tienen un nivel de licenciatura. Supone globalmente un capital humano en situación de empleo precario, no muy bien pagado, temporal y femenino ${ }^{24}$. Las/os trabajadores de servicios sociales, que se dedican a atender a personas en situaciones precarias, tienen ellas mismas una situación de precariedad en el empleo.

Se observa una tensión entre esta red pública del Plan Concertado basada en municipios y Comunidades Autónomas, y otras redes paralelas privadas como la de Cáritas basada en $p a-$ rroquias y diócesis. Coexisten ambas con poca coordinación. Cada organización tiende a especializarse en unos servicios. Cáritas aparece monopolizando el tema de pobreza, no sólo en su atención sino incluso en su definición y análisis empírico. Cáritas es una red que experimenta un gran expansión, en parte debida a la financiación pública. En 1992 mantiene 137 acentros de acogida" lo que supone un crecimiento de casi seis veces respecto de los que tiene una década antes. Triplica el número de personas atendidas en esos centros (que llega a casi 58.000), y un $87 \%$ más de personas asistidas en albergues (llegando a casi 40.000 en 1992).

Hay otras redes que son menos extensas, y más especializadas. En el sector público destaca el Inserso, que atiende a domicilio a personas ancianas y a personas minusválidas. En ambos casos en sólo cuatro años, 1988-1992, se triplica el número de personas atendidas, alcanzando más de 26.000 ancianos/as y 1.700 minusválidos/as. Hay que tener en cuenta que los servicios de atención básica a personas con minusvalía del Inserso atienden en 1991 a más de 400.000 personas, el 62\% recibiendo información (orientación), y el 32\% con un diagnóstico de valores de las situaciones de minusvalía.

Muchos de los servicios sociales llamados "especializados" dependen de situaciones que van cambiando en parte debido a las transformaciones de la estructura demográfica. Éste es el caso de la definición de grupos vulnerables debido a la edad: los muy jóvenes (infancia) que disminuyen mucho en número o los muy mayores (ancianidad) que no hace más que aumentar. A su vez, eso depende de la estructura de noviazgo-matrimonialidad-natalidad. Esos factores demográficos y familiares cambian mucho debido a la crisis económica que se inicia en 1973. La cifra de matrimonios en los años noventa es bajisima. En la década de los ochenta la tasa de nupcialidad desciende un 6\%, y la de natalidad un 32\%. Dado que las defunciones (debido al proceso de envejecimiento) aumentan un $8 \%$ en el mismo período, el crecimiento vegetativo desciende un $73 \%$ en esa década. Cada vez hay menos familias, menos personas que se casan, y sobre todo menos mujeres (o familias) que tienen hijas/os.

A pesar de estos cambios recientes a finales del siglo XX la familia sigue siendo la primera institución de servicios sociales en la sociedad española. Por supuesto, no todas las familias son iguales. Es un dato empírico que las familias de clase baja son más ayudadoras que las de clases altas. Este hecho tiene varias lecturas. (a) Las familias pobres tienden a ser más ayudadoras porque tienen más situaciones de precariedad entre sus miembros. (b) A eso contribuye el que además son más extensas, tienen así más miembros en posibles situaciones de precariedad, y menos ingresos per capita. (c) Quizás es que las familias de clases más bajas sean más generosas. (d) Es posible también que sean más pobres precisamente porque son más altruistas. La realidad es una combinación de estas cuatro hipótesis.

Algunos datos de encuesta - poco fiables en temas de servicios sociales pero al menos indicativos de los cambios que se van produciendo- muestran estas diferencias entre familias de clase alta (alta y media alta según la terminología de aclase social subjetiva") y de "clase pobre". Las familias pobres muestran lógicamente una insuficiencia grave de dinero para mantener el hogar en mucha mayor proporción ( 58 veces más que las altas), lo cual es tautológico pues se refiere a la propia definición de pobreza. Tienen seis veces más algún miembro con problemas de drogadicción, cinco veces más con experiencia de cárcel, y tres veces más alguna persona con minusvalía. De nuevo no queda claro si la definición de situaciones precarias depende de la clase social o es más bien al revés.

A pesar de que la natalidad en España en los años noventa está en un mínimo histórico (y mundial) la población infantil no desciende mucho. Tarda lógicamente unos años en reducir la proporción. Entre 1960 y 1981 el número de niños/as de cero a catorce años aumenta un 16\% en números absolutos. Pero en la década siguiente, censos de 1981-1991, se observa un descenso acusado de un 22\% en datos absolutos. En 1991 hay 7,5 millones de personas de 0-14 años en España. Pero aunque el número descienda, la infancia en servicios sociales no es un problema de números absolutos, sino más bien de lo que podría llamarse ainfancia en dificultad social. Esta infancia con problemas se puede estimar a partir de los datos del Defensor del Pueblo, y de los Tribunales Tutelares de Menores.

Durante los años ochenta (datos para 1980-1987) casi se triplican los casos de protección de menores (expedientes falladosn), aunque descienden algo (el 14\%) el número de menores sometidos al Tribunal, quienes apenas sobrepasan los 10.000 en 1987. Se juzgan menos menores, pero se duplica la suspensión del derecho a la guarda y educación de esos menores, e incluso se separa bastante más a algunos menores de sus guardadores de hecho. Al final de la década de los ochenta los centros de protección de menores acogen a más de 18.000 menores en unos 8.000 centros, lo que representa que sólo están ocupadas un $62 \%$ de las plazas disponibles de ese tipo de centros.

Los casos de protección no aumentan sino que van descendiendo, el número de expedientes desciende un 14\%, aunque la efectividad parece cada vez mayor. Los casos de función reformadora sobre menores sí que aumentan en los años ochenta; 
el número de expedientes experimenta una elevación del $6 \%$ entre 1980 y 1989. El número de menores sometidos al Tribunal aumenta un 36\%. La acción de internamiento de esos menores desciende bastante: un $53 \%$ en la misma década, se pasa de 5.625 menores en 1980 a 2.662 en 1989. La razón es que cada vez crecen más las cifras de libertad vigilada. Al final de la década los menores (son sobre todo varones) en centros de reforma son 867 (en 44 centros), es decir, el $82 \%$ de las plazas disponibles. De los 7,5 millones de infantes (0-14 años) en España hacia finales de los años ochenta hay menos de 20.000 en centros específicos. En todo caso, el $96 \%$ están en centros por motivos de protección, y sólo el $4 \%$ restante por razones de reforma, aunque protección/reforma es una frontera menos clara de lo que parece. Falta una visión sociológica general sobre el tema de menores con problemas legales ya sean de protección como de reforma.

La juventud es otra etapa vital en que los servicios sociales son sólo necesarios en situaciones extremas. Durante todo el siglo XX las personas jóvenes son cada vez más en número en España, pues la bajada de natalidad todavía no influencia mucho al grupo de edad de 15 a 24 años. En 1960 ese grupo de edad supone el 15\% de la población. Es lo mismo que en el censo de 1970, aumentando al 16\% en 1981, y al 17\% en 1991. En este grupo social una tasa de desempleo alta como la existente puede producir problemas colaterales como delincuencia o toxicomanía. En el caso de mujeres está relacionada además con embarazos inconvenientes (depende de cómo y quién defina ese término) y prostitución.

La combinación de juventud que no disminuye en número y de ancianidad que aumenta mucho supone una tasa de población dependiente cada vez mayor. En 1991 la proporción de jóvenes de 15 a 24 años, más la de personas ancianas de 65 y más años, suponen un $31 \%$ de la población, que tres décadas antes era sólo el 23\%. El proceso de envejecimiento es sin duda una característica altamente optimista de la sociedad actual: las personas viven más años, más personas viven más años y más personas viven una vida mejor. Por eso sorprende una cierta tendencia a considerar todo ese proceso bajo una luz pesimista: la ancianidad supone un número creciente de personas en situaciones precarias, de exclusión, supuestamente ainfelices", y sobre todo de enfermedad crónica. Concentran recursos en sanidad (de cuatro a siete veces más que el promedio de la población), y sobre todo en servicios sociales. Otros grupos sociales están estables, o varían lentamente, pero la natalidad desciende mucho, y al mismo tiempo la ancianidad se prolonga a nivel individual y se hace más numerosa a nivel colectivo. Desde 1900 hasta 1940 la proporción de personas de 65 años y más es prácticamente estable, aumentando sólo ligeramente del $5 \%$ al $6 \%$. En los siguientes cuarenta años está proporción se duplica al 11\%. Entre 1981 y 1991 pasa de representar el 11\% al
14\%. El proceso de envejecimiento de la sociedad es pues acelerado al final del siglo XX.

Tradicionalmente las personas ancianas eran antes responsabilidad de la familia. Sus necesidades de servicios sociales se consideraban bastante reducidas no sólo porque la población anciana era tres veces menor, sino porque además la familia cumplía con esos servicios, y los ancianos/as duraban pocos años. Existían asilos de ancianos/as para las personas pobres, o las que no tenían familia que pudiesen cuidarles. La situación cambia progresivamente dando tiempo a que la sociedad cree instituciones que atienden a una cantidad cada vez mayor de personas ancianas. En 1970 se crea el Servicio Social de Asistencia de los Ancianos, y al año siguiente se diseña el Plan Nacional de Asistencia a los Ancianos. Se refiere siempre a ancianas y ancianos, pues otra de las tendencias es que cada vez son más ancianas que ancianos. La esperanza de vida se alarga, y se requieren residencias para ancianos/as incapacitados, que no pueden (ni deben) ser atendidos en hospitales públicos. En 1993 el MAS propone un primer Plan Gerontológico.

Todo esto supone una expansión de servicios sociales para las personas ancianas. Pero la cantidad relativa de camas en residencias para esa "tercera edad. no aumenta mucho. Está estabilizada en torno al.2\% de camas en residencias en relación a la población de 65 y más años: eran 1,3\% en 1963, y son ya el $2,0 \%$ en 1982 , sube un poco al 2,2\% en 1988 , y vuelve al $2,0 \%$ en 1991. Es posible que los cambios sociales y de estructura familiar de final del siglo XX fuercen a este sector a expandirse. Mientras tanto, la familia está sirviendo de colchón, como proveedora de servicios sociales y de estructura cuidadora no sólo para los ancianos/as sino además para las personas en paro. La cuestión es hasta cuándo puede la familia en Espana cumplir esa función cuidadora con la escasez de recursos con los que cuenta.

Otro grupo de personas con necesidades de servicios sociales especializados lo son eufemísticamente por su "condición sexual. Esto suele referirse fundamentalmente a prostitución femenina, y en menor medida a otras minorías sexuales. Durante el franquismo el Ministerio de Justicia mantenía una institución dedicada a mujeres con estos problemas denominado Patronato de Protección a la Mujer. Sus cometidos eran: ala protección de las jóvenes frente a riesgos morales y sociales; el fomento de la persecución del tráfico y comupción de menores, 'trata de blancas', pornografía y difusión de prácticas anticonceptivas y abortivas; la regeneración de mujeres caídas, incluyendo internamientos de asistencia y control. ${ }^{25}$. Muchas de esas funciones encomendadas en 1952 se cumplen luego a través de otras organizaciones fundamentalmente sanidad, centros de planificación familiar, centros de orientación familiar, leyes de internupción voluntaria del embarazo, acción policial, y Tribunales de Justicia. 
Las dos primeras décadas de la nueva democracia no suponen un progreso evidente en estos temas. Hay pocas posibilidades reales de medir la prostitución, pues es un fenómeno social estilo iceberg, cuya parte oculta es difícil de evaluar. Algunos sociólogos reconocen que: ‘La observación común parece indicar que la prostitución no ha decrecido, sino que viene extendiéndose. El recurso a la misma para financiar el consumo de droga puede ser uno de los factores en juego. Las intervenciones relativas a las personas prostituidas, en cambio, parecen haber experimentado una decadencia general. Seguramente, por causa de un conflicto ideológico irresuelto no se han adoptado políticas públicas resueltas. En un período dominado por el intervencionismo de los organismos oficiales, apenas se registra alguna iniciativa de acción directa ${ }^{26}$. Se produce además una conexión entre prostitución y drogas, así como entre ambas y sida. La antigua aresponsabilidad pública" respecto de la prostitución casi desaparece, sustituyéndose por un interés más general sobre la condición de la mujer. Al año siguiente de la entrada del PSOE en el Gobiemo se crea el Instituto de la Mujer, cuyo objetivo va más dirigido a la igualdad de la mujer, la participación femenina en la vida pública y en el mundo laboral.

Tampoco hay una política clara de servicios sociales respecto de personas homosexuales (no queda claro si eso sería preferible). La población general sigue manteniendo posturas ambiguas, aunque el proceso de tolerancia es cada vez mayor sobre todo entre personas jóvenes. La encuesta de 1993 señala que todavía un $2 \%$ de la población considera a las personas homosexuales como delincuentes, y un $21 \%$ como enfermas. En total, una de cada cuatro personas mantiene actitudes explícitamente intolerantes. Hay que tener en cuenta que son contestaciones orales a un entrevistador, y por lo tanto supuestamente sesgadas. Quizás el que no haya una política de servicios sociales especializada para estos grupos de población sea positivo, por el potencial de generación de guetos que pueden tener esas políticas.

En el sector de servicios sociales español se habla de aminorías étnicas" para referirse no a las personas de otras etnias que cada vez son más frecuentes en España- sino a la única etnia distinta que permanece constante, que es el grupo gitano. Es aproximadamente un $1 \%$ de la población española, más prevalente en el sur de la península y en torno a las grandes ciudades. Son ciudadanos/as españoles, y ésa es una característica importante a tener en cuenta. Entra también una población gitana de origen portugués. La población gitana concentra necesidades de todo tipo de servicios sociales. El sector público evoluciona desde una idea asimilacionista y de integración social a una de tolerancia, y, más recientemente, de multiculturalismo. Al inicio de la democracia se crea una Comisión Interministerial para Asuntos Gitanos. En 1989 se pone en mar- cha desde el Gobierno un Plan de Desarrollo Gitano con unos recursos muy limitados (aproximadamente 500 millones de pesetas anuales). Al igual que la pobreza el tema de la población gitana se redescubre cada cierto tiempo, se pone de moda y se vuelve luego a olvidar durante unos años. A finales del siglo XX la política no es asimilacionista, aunque tampoco es plenamente multiculturalista.

Las minorías étnicas extranjeras, es decir, sin nacionalidad española, es un tema un poco diferente, cada vez más importante. España pasa de ser un país de emigrantes a serlo de inmigrantes. Además, cada vez más la población inmigrante proviene del Tercer Mundo. Los datos sobre esta realidad son limitados, pues las estadísticas de extranjeros/as residentes legales son sólo una parte de la realidad, quizás la menos importante numéricamente en relación a los servicios sociales. En 1991 hay en España unos 360.000 extranjeros residentes (legales), es decir, una cantidad algo menor que gitanos/as ${ }^{27}$. En una década, 1982-1991, el número de extranjeros/as se incrementa un $80 \%$. La mitad provienen de Europa, pero esa proporción desciende. En 1982 los/as europeos suponen el 66\% de todos los extranjeros/as residentes; en una década el incremento de europeos/as es tan sólo del 35\%, comparado con el. $80 \%$ de incremento de americanos/as (norte y sur), y el $124 \%$ de incremento de asiáticos/as. Los extranjeros provenientes de África aumen$\tan$ doce veces en número en la década de los ochenta. En 1991 los 63.000 africanos/as representan sólo el 17\% del total de extranjeros residentes, pero su número aumenta a gran velocidad.

Las personas con deficiencias o con minusvalía conforman una población diana para el sector de servicios sociales ${ }^{28}$. Es aproximadamente un 15\% de la población según la macroencuesta que en 1986 realiza el INE. Un 5\% de la población presenta deficiencias del aparato locomotor, otro tanto deficiencias físicas, un $2 \%$ de la audición, y una proporción similar de la vista. Se utiliza un sistema de progresión denominado de adedimí que va desde la deficiencia a la discapacidad, y de ésta a la minusvalia. Hay igual número de personas con deficiencias y discapacidades, pero un $9 \%$ de ellos/as no se convierten luego en personas con minusvalía. En España (en 1986) hay aproximadamente un $14 \%$ de personas con minusvalía, un $5 \%$ de minusvalías referentes a ocupación, un $2 \%$ de movilidad, y otro tanto casi de independencia física. La encuesta recoge también un $2 \%$ de población con minusvalía de aintegración social. y otro tanto de personas con ainsuficiencia económica. Estos dos factores (exclusión y precariedad) son precisamente los dos básicos que conforman el sector de servicios sociales.

Algunos grupos sociales (como el 2,13\% de la población total con deficiencias de la vista) generan en Espana organizaciones que se dedican a su cuidado, nivel económico (incluso de empleo), e inserción social. En 1938 se crea en la zona fran- 
quista la Organización Nacional de Ciegos de España, la ONCE como es conocida, una de las instituciones sociales de mayor poder actualmente en el país ${ }^{29}$. Otras deficiencias y discapacidades no están tan atendidas. En 1974 se pone en marcha el SEREM - Servicio de Recuperación y Rehabilitación de Minusválidos Físicos y Psíquicos - y ocho años después se promulga la Ley de Integración Social de los Minusválidos, conocida como la LISMI. Más específicamente existe una Federación Española de Asociaciones Pro Subnormales, FEAPS ${ }^{30}$. A su vez, el Inserso mantiene varios Centros de Rehabilitación de Minusválidos Físicos y otros varios Centros de Atención a Minusválidos Físicos.

El inicio de las dos últimas epidemias importantes en España coincide en el año 1981. Son la del sindrome tóxico por envenenamiento de aceite de colza adulterado (STE), y el sindrome de inmunodeficiencia adquirida o sida por el $\mathrm{VH}+$. El STE es una epidemia puntual, que afecta en total a unas 20.000 personas, y no se reproduce pues la supuesta causa es un envenenamiento por aceite adulterado. El sida aunque empieza en 1981 (con un caso) tarda varios años en llamar la atención. Se contabilizan en 1996 ya más de 40.000 casos, un 19\% son mujeres ${ }^{31}$. Por lo menos, en un $65 \%$ de los casos la transmisión es por jeringuillas (son UDVP, es decir, usuarios de drogas por vía parenteral). Ambas epidemias tienen efectos considerables en las necesidades de servicios sociales.

El sida, la delincuencia y la prostitución están estrechamente relacionadas con toxicomanía. El problema de ulas drogas muy poco importante durante la dictadura franquista- se desarrolla considerablemente en España en los años ochenta y noventa. Los datos que se manejan son poco exactos y generalmente increibles. Una encuesta de 1992 señala que la población que reconoce haber consumido marijuana (cannabis) en el último mes es el $4 \%$, cocaína el $2 \%$ y heroína $1,3 \%$. Las encuestas generales de la población, con muestras de 2.250 personas, no son válidas para este análisis, pero presentan una sensibilización de la población sobre esos temas. En 1985 se pone en marcha el Plan Nacional sobre [contra las] Drogas, que incluye la figura de un Delegado del Gobierno para el PND. Se refiere fundamentalmente a drogas ilegales, pues el tabaco y el alcohol siguen siendo socialmente aceptadas, y sobre las que las políticas gubernamentales de impuestos tienen poco efecto. Las drogodependencias es un sector de negocio creciente no sólo para los traficantes y "camellos. En seis años (1986-1992) los servicios de unidades hospitalarias dedicadas al tema se multiplican por cinco, los centros ambulatorios por cuatro, los centros de metadona 13 veces y las comunidades terapéuticas se duplican en número (pasan de 41 a 79). Es un área de atención especializada, que muestra las ventajas de una unión de los servicios sanitarios con los servicios sociales.

El tema de pobreza es recurrente en el análisis de la desigualdad social, así como en la conciencia colectiva de la socie- dad. Es un tema que se analiza (a) como derivado de la estructura social que lo genera, (b) que tiene que ver con la política de rentas ya que la pobreza se define operativamente como una medida de dispersión de ingresos familiares, y (c) con el sector de servicios sociales que es el que se encarga de que no cree situaciones extremas, exclusión total, o morbilidad/mortalidad. Es un tema que está de moda en los años sesenta, que durante la transición política pierde actualidad, y que con la crisis económica y el desempleo retoma actualidad en los años noventa. Desde mediados de la década de los ochenta Cáritas se dedica al tema, casi como un monopolio propio. El Plan Concertado estatal dedica también una proporción de sus esfuerzos a combatir la pobreza y sus consecuencias. En ambos casos la evaluación de la acción es mínima. Se gastan recursos pero no se mide el impacto de los mismos.

Las definiciones de pobreza que se utilizan son medidas de desigualdad económica. Las familias por debajo del $50 \%$ de los ingresos medios suponen en España un 20\% de la población (el 19\% hacia la mitad de la década de los ochenta), es decir, una quinta parte más alta que en la vecina Francia. No es fácil reducir la pobreza si no se transforma la estructura de distribución de la propiedad y de riqueza en el país. Cambiar la estructura social (y no sólo económica) es una tarea ingente, que no queda claro cómo puede ser abordada. Desde los servicios sociales públicos o privados, concertado o no- es imposible.

Este $20 \%$ de población pobre supone ocho millones de españoles/as, cantidad mítica que crea polémicas considerables en varias ocasiones. Curiosamente, este porcentaje coincide en los últimos años con la proporción de desempleo, estimada entre $18 \%$ en 1983 y $21 \%$ en 1996 . Se refiere a paro de la población activa. No son cifras que coincidan en las personas: hay ocho millones de pobres/as y tres millones de desempleados/as. La pobreza es una proporción estable: se estima que representa el $20 \%$ de la población total en 1974 , el $20 \%$ en 1981, y 19\% en 1991. Es un indicador de la estructura de la desigualdad, y no una medida real de personas spobres de solemnidad.

El desarrollo de los años sesenta y setenta reduce el enfoque comunitario tradicional que existe sobre ese tema: ‘El desarrollo económico alivió el peso de la pobreza y ofreció un cauce de salida hacia el exterior de las bolsas locales. La cultura desarrollista, por lo demás, parece que vino a menguar la valoración del enfoque local. Tras la muerte de Franco, el problema de la pobreza quedaría oculto tras los asuntos políticos de aquella coyuntura histórica. Por otra parte, la ideología de la distribución como mecanismo solucionalotodo, tan pujante desde entonces, vino a debilitar la motivación y la creatividad localistan ${ }^{32}$. La perspectiva 0 acción comunitaria se denomina "enfoque local. y acreatividad localista. Se abandona la tradición de programas puntuales, en polos (de desarrollo), para tender a 
visiones de Planes Concertados globales para todo el territorio. Incluso se piensa seriamente en crear una red de servicios sociales para toda la población y no sólo para las personas excluidas/pobres.

La innovación de los últimos años es tender hacia un sistema alternativo de salarios, el IMI o RMI, como un cambio revolucionario dentro de los servicios sociales ${ }^{33}$. La primera experiencia se realiza fuera del Plan Concertado, por el Gobierno del País Vasco. En 1988 presenta el Plan Integral de Lucha contra la Pobreza, y al año siguiente el ingreso minimo familiar (IMF). No sólo se trata de apoyo económico complementario a las familias elegidas por el programa, sino también para su reinserción social y su promoción. La puesta en marcha de este programa alcanza a 11.000 familias en el País Vasco. Cuatro años más tarde el sistema de IMI se generaliza a todas las Comunidades Autónomas, a excepción de Islas Baleares. No existe todavía una experiencia suficiente como para poder evaluar su impacto real en la reducción de la pobreza global.

Los servicios sociales experimentan un proceso de descentralización. Es un tema que corresponde a las Comunidades Autónomas, pero que es aplicado por los municipios. La provincia prácticamente desaparece. En el caso de Cáritas es un proceso de descentralización relativa en diócesis y parroquias. El sector público —originalmente en el MAS, luego en el MiTAS-organiza el Plan Concertado, del que no forman parte ni Navarra ni el País Vasco; tampoco Ceuta ni Melilla. Cada Comunidad Autónoma incorpora al Plan Concertado los centros y personal que estima oportuno. En realidad, el proceso progresivo de incorporación al Plan Concertado es poco "concertadon. Hacia 1991 las diferencias del número de centros es por lo menos de 18 veces entre la Comunidad Autónoma más equipada (Extremadura) y la que menos (Comunidad Valenciana). Las diferencias en presupuesto por habitantes es del triple entre los extremos. La población por centro es de unos 46.000 habitantes de media, y el gasto apenas 836 pesetas por persona y año. No son cantidades muy importantes ${ }^{34}$ :

Las diferencias regionales en recursos reales (pesetas por habitante) según Comunidades Autónomas en el Plan Concertado estatal son del triple: Islas Baleares la mejor, Comunidad de Madrid la peor. En otros indicadores como la ayuda a domicilio a ancianos/as del Inserso, que atiende al 1\% de la población diana, son del cuádruple: Extremadura la mejor, Asturias la peor. Igualmente del cuádruple son las diferencias en la ayuda a domicilio del Inserso para minusválidos/as; en este indicador Extremadura y Madrid son las peores. Las diferencias por Comunidades Autónomas son poco coherentes. No representan supuestamente estados de necesidad especiales, tampoco reflejan niveles de riqueza ni de desarrollo. En cada indicador las Comunidades Autónomas en buena y mala situación van variando. No se aprecia una pauta consistente.
En otros indicadores de servicios sociales especializados esta situación confusa es similar, pues se refiere a colectivos más reducidos. Las diferencias regionales de guarderías laborales (supone al año menos de 700 pesetas por menor de 0.5 años) son del doble: Extremadura tiene la peor situación. El gasto en atención a la primera infancia presenta diferencias de hasta 42 veces. Los hogares y clubes para ancianos presentan diferencias de ocho veces (la peor es Asturias). Los hogares y clubes del Inserso muestran diferencias regionales de cinco veces; la mejor es Extremadura y la peor Madrid.

Un tema importante es el de las plazas de asilos para ancianos/as. El número de plazas varía poco: pasa de 1,4\% respecto de la población anciana total del país en 1963 , a un $2 \%$ estable en 1982, 1988, y 1991. La situación parece mejorar, pues aumenta un $46 \%$ la tasa de camas. Disminuye además las diferencias regionales: de seis veces en 1963, a cuatro veces en los años ochenta, y a tres veces de diferencia en 1991. Las desigualdades regionales decrecen pues un $48 \%$. Cada vez hay más plazas, y están mejor distribuidas. Hay más asilos de ancianos/as porque las familias cuidan menos de sus abuelos/as.

En España en 1991 de los 5,4 millones de personas de 65 y más años aproximadamente 110.000 viven internos en una residencia, es decir, el 2\%. Se observan diferencias regionales significativas. Las regiones con muchos ancianos/as internos en residencias están en el norte desarrollado: Navarra, La Rioja, Aragón, País Vasco, e incluso Castilla y León. En cambio, las regiones que tienen pocos viejos/as en residencias corresponden fundamentalmente a la España menos rica como Galicia y el sur: Canarias, Murcia, Andalucía, Extremadura, hasta Comunidad Valenciana. La España pobre, sureña, tiene menos recursos, pero cuida bastante más de sus abuelos/as en el hogar. No es pues un tema de dinero, sino de pautas culturāes y familiares. Esto explica las diferencias de 3,3 veces entre Navarra (4\% de ancianos/as en residencias) y Canarias (1\%). Los créditos oficiales del Plan Gerontológico, en 1993, tratan de superar esta estructura. Aunque no hay grandes diferencias de créditos por regiones (1,4 veces únicamente) las que reciben más créditos son precisamente las de la España pobre y del Sur: Canarias, Galicia y Extremadura por ese orden. Las Comunidades Autónomas que menos dinero reciben por población anciana son Madrid y Cataluña.

El Plan Nacional sobre Drogas (debería ser contra las drogas) presenta diferencias menos explicables, que no parecen correlacionar con estados de necesidad. La tasa de población atendida ambulatoriamente varía 13 veces de una región a otra (calculada sobre la población total). Se concentra igualmente en el Sur: Canarias y Andalucía; pero las siguientes regiones son Baleares, Galicia y País Vasco. En cambio, la tasa de población atendida en comunidades terapéuticas varía 17 veces de una región a otra, y se concentra mayoritariamente en el norte: Navarra, Asturias, País Vasco, La Rioja, Islas Baleares. Los drogadictos/as 
atendidos externamente son 14 por diez mil habitantes. Los internados son 1,3 por diez mil habitantes (el $9 \%$ de los usuarios/as de centros ambulatorios).

Globalmente, el gasto público del MAS en servicios sociales en las Comunidades Autónomas en 1992 es casi 326.000 millones de pesetas. De esa cantidad estimable conviene restar los subsidios económicos del LISMI y las pensiones no contributivas (que son aproximadamente la mitad, el 49\%). Así, el saldo supone unas 4.600 pesetas por habitante al año ${ }^{35}$. Las diferencias regionales son de 4,3 veces. La Comunidad Autónoma que más recibe es Extremadura que coincide con ser la más pobre y necesitada de toda España. Las siguientes son por orden: Castilla y León, Murcia, Aragón. La Comunidad Autónoma que menos presupuesto público tiene en servicios sociales es Canarias, y luego Comunidad Valenciana, Cataluña y Andalucía. No está, pues, clara la forma en que se distribuye el dinero por Comunidades Autónomas. No se aplican criterios estrictos de pobreza, problemas sociales, ni desarrollo. Tampoco parece que con estos indicadores sintéticos el Estado (aquí concretamente el MiTAS) sirva de institución redistribuidora de desigualdades regionales. Hay que tener en cuenta que no se mide tampoco la efectividad real de ese gasto. Es precisa una política más clara para el siglo XXI.

\section{Red básica del sector público}

La familia sigue siendo la primera institución cuidadora y de servicios sociales en España. También es la generadora o cristalizadora de las desigualdades sociales de la población. En los años noventa absorbe el paro (21\%), dedimí, problemas familiares de minusvalía, pobreza, toxicomanías, cuidado de ancianos/as y problemas individuales de todo tipo. Las encuestas calculan en 1993 que un $9 \%$ de familias están dando atención extraordinaria en el propio hogar a alguno de sus miembros: Las familias más pobres son las más ayudadoras: cuidan cuatro veces más a hijos/as con discapacidades graves, y a enfermos/as crónicos, y tienen el doble de veces una persona anciana dependiente viviendo en el hogar ${ }^{36}$. La sorpresa es que la estructura familiar cuidadora apenas varía por clase social. Los padres ayudan a los hijos (20\%) el doble de veces que la situación inversa (10\%). Los padres viven en casa de sus hijos (6\%) más que los hijos casados en casa de sus padres (4\%). Todos estos datos son para varones y mujeres. Lo llamativo es que los padres ayudan a los hijos/as casi por igual en todas las clases sociales. Sin embargo, en las clases más bajas los hijos/as ayudan más a sus padres ancianos. También es verdad que en la clase baja los hijos/as casados viven más con sus padres. Apenas hay diferencias en la proporción de padres mayores que vi- ven en el hogar de un hijo/a: es constantemente un $6 \%$ sin apenas diferencias por clase.

Todo sugiere que la familia española está haciendo un esfuerzo cuidador importante, sobre todo en el caso de las generaciones mayores ayudando a las más jóvenes. La proporción de ancianos/as que son cuidados por sus familiares, así como la ayuda de los padres a los hijos/as, no muestra diferencias por clase social. .Tanto desde un punto de vista técnico como por razones éticas, no parece aceptable cargar a la familia con cuidados estresantes sin prestarle servicios de apoyo. La atención de un hijo con deficiencia mental profunda, la incorporación social de un familiar enfermo mental, la tutela de un cónyuge afectado de Alzheimer o la asistencia a una madre -decimos madre por la mayor longevidad femenina - dependiente puede rebasar la capacidad psíquica y física de una persona y de una familia. La permanencia en el hogar, en tales casos, requiere apoyos sólidos, no reductibles a una ayuda domiciliaria de un par de horas a la semana o a la visita ocasional de unos jóvenes voluntarios. Hacen falta centros de día, centros de internamiento ocasional, apoyos económicos, terapia familiar, etc., que apenas si se están iniciando. El concurso masivo de la familia en la acción social requiere un nuevo trato social. El asunto no es reductible a ideología solidarista, mentalización social, retórica neofamilista o voluntarismo " ${ }^{37}$. Este párrafo resume bien el objetivo fundamental de los servicios sociales que pueden ayudar a las familias -y personas- que están dedicando esfuerzos considerables a paliar el paro, la pobreza, la enfermedad, minusvalía, desviación, marginación social, exclusión. Idealmente es esta población la que debería diseñar los programas de acción social, conforme a sus necesidades reales.

Si se puede hacer caso de los datos de encuesta, que en estos temas son bastante inexactos, aproximadamente un $6 \%$ de las familias españolas utilizan servicios sociales ${ }^{38}$. La mayoría señala servicios para ancianos/as (el 1,5\%) pero son porcentajes bajos. Las diferencias de utilización general de servicios sociales está lógicamente relacionada con la clase social, pues es un elemento de igualación social. Las diferencias reales observadas no son tan elevadas. Utilizando datos de clase social subjetiva (encuesta de 1993) la clase alta y media alta utiliza servicios sociales un $4 \%$, mientras que los hogares que se identifican como de clase "pobre utilizan los servicios sociales en un $14 \%$ de los casos. Las diferencias son de 3,2 veces, pero el $4 \%$ parece alto para ser el $6 \%$ de hogares más ricos de la sociedad española. Por otro lado, sólo un $14 \%$ de los/as autoidentificados como "pobres -el 2\% de la población total- utilizan servicios sociales lo que parece inexplicablemente bajo. O los servicios sociales no están cumpliendo su objetivo fundamental redistribuidor de las desigualdades, o estos datos son poco fiables ${ }^{39}$.

El sector privado —en su mayoría sin ánimo de lucromantiene un sector extenso de voluntariado. Es el caso sobre 
todo de macroorganizaciones como Cáritas española o Cruz Roja Española. Algunos/as investigadores sociales expertos en temas de servicios sociales realizan una crítica razonada al desarrollo del voluntariado en España, señalando que recientemente asistimos a una visible explosión de amor por el voluntariado y las organizaciones voluntarias [....] Tras la muerte de Franco, y hasta muy avanzados los años ochenta, lo privado social $-\mathrm{y}$ más aún lo mercantil- fue considerado por un amplio sector ideológico de dudosa legitimidad en el Estado de Bienestar pendiente [....] las entidades voluntarias españolas financian una gran parte de sus actividades y aun de su mantenimiento organizativo con caudales públicos. Aportan cuantiosos recursos propios - sobre todo humanos-, pero también son un factor de excitación y ampliación de la demanda, de modo que no es seguro que vengan suponiendo un alivio monetario a las Administraciones Públicas" ${ }^{40}$. Del total de la población un $4 \%$ señala que se dedica personalmente a labores de ayuda personal voluntaria fuera del bogar, un 7\% (se supone que incluyen a las personas anteriores) participan de alguna manera en organizaciones de voluntariado, y un $18 \%$ contribuye económicamente. Como es esperable, estos porcentajes correlacionan positivamente con clase social. El 6\% más alto de la sociedad (en una variable de autoidentificación) se dedica al voluntariado personal cinco veces más que el $2 \%$ más bajo de la sociedad; participa en organizaciones el doble, y contribuye económicamente el triple. Estas diferencias son lógicas pues es la forma institucionalizada de que la clase alta ayude a la clase baja dentro de la sociedad. Lo llamativo es que las diferencias no sean más grandes. Una décima parte del $2 \%$ de los hogares más pobres contribuyen económicamente a las obras sociales voluntarias, lo que parece un sinsentido, pues son esos hogares precisamente los que deberían recibir ayudas y servicios. Las diferencias por clases sociales no están claras. Cuando se investiga esta contribución según la religiosidad llama la atención que las personas que participan más en el voluntariado son las que se consideran religiosas pero que $n o$ son católicas ${ }^{41}$.

Las macroorganizaciones voluntarias, actualmente denominadas $\mathrm{ONG}$, representan una actividad importante en el área de los servicios sociales. Hacia 1992 la Cruz Roja tiene un presupuesto aproximado de 33.000 millones de pesetas; la Obra Social de las Cajas de Ahorro en el área asistencial supone 12.500 millones de pesetas aproximadamente; y Cáritas española 10.500 millones de pesetas. El total de 56.000 millones representa el 34\% de los 165.500 millones de presupuesto del Ministerio de Asuntos Sociales para servicios sociales en la misma fecha. Entre tres organizaciones grandes se realiza, pues, acción social equivalente a un tercio de la que se encarga el sector público. La Obra Social de las Cajas de Ahorro se concentra más en lo cultural, dejando para lo realmente social (área asistencial) el $23 \%$ de sus actividades y presupuesto. A estas tres ma- croorganizaciones habría que añadirle alguna otra como la ONCE para ciegos/as.

Un $43 \%$ de las fundaciones españolas, según el censo de fundaciones, se dedica directa o indirectamente a beneficencia, asistencia social y desarrollo comunitario (son un total de 853 fundaciones en 1992). Muchas de estas organizaciones viven del Estado, de la contribución para atros fines de interés social. de la declaración del IRPF y de la población. A menudo viven de las propias personas que atienden, o de una clase o estrato social similar ${ }^{42}$. Se insinúa a veces la crítica de que esta financiación del Estado a organizaciones privadas es en el fondo una forma confusa de contratación externa ${ }^{43}$. De esta forma, alas proclamadas virtualidades de la acción voluntaria en cuanto a creatividad y el pionerismo se anulan en gran parte; es la iniciativa pública la que marca áreas y objetivos ${ }^{44}$. El sector privado vive del público, pero además se encarga de las tareas que el sector público no alcanza a realizar, o para las que no tiene personal ni voluntariado adecuados.

Hasta 1988 que el Estado -el MAS - pone en marcha el Plan Concertado, la expansión del sector de servicios sociales (si se pone en relación con el PIB) no crece mucho. El presupuesto de asistencia social de los Ayuntamientos entre 1972 y 1988 en porcentajes del PIB crece un 50\%. El presupuesto de Diputaciones y Cabildos aumenta un poco más (el 150\% en estos 16 años, siempre en relación con el PIB). En parte este crecimiento no espectacular se debe a que a partir de 1984 se producen ya las transferencias de servicios sociales del Estado a las Comunidades Autónomas. Entre 1984 y 1988 el presupuesto (consolidado) de servicios sociales de las Comunidades Autónomas crece 2,7 veces en relación con el PIB. El énfasis se pone pues en la acción de las Comunidades Autónomas que absorben el $54 \%$ de la actividad pública en servicios sociales, dejando un 29\% para Diputaciones y Cabildos, y sólo un 17\% para los presupuestos de los Ayuntamientos. A partir del Plan Concertado, sobre todo después de los primeros años, es decir, en la década de los noventa, el sistema se estructura de forma diferente, con un control mayor por parte de las Comunidades Autónomas, pero una ejecución de la acción social a nivel de los municipios. Otros sectores públicos ven descender progresivamente sus presupuestos relativos en esas fechas (1972-1988) como resultado del cambio general en la política autonómica: el Inserso desciende un 33\% su presupuesto respecto del PIB, o incluso la Dirección General de Acción Social (DGAS) desciende un $75 \%$ sus gastos corrientes y un $83 \%$ sus gastos de capital. Este hecho se debe a las trasferencias del Instituto Nacional de Asistencia Social a las Comunidades Autónomas.

El desarrollo de una inversión fuerte en políticas de servicios sociales explica el déficit histórico del Estado en la creación de políticas de atención social. El logro más significativo del Plan Concertado es que en diez años se ofrece a casi la to- 
talidad de la población de quince Comunidades Autónomas una red de atención gratuita. Se trata de un esfuerzo por destinar partidas presupuestarias suficientes -tras la creación del Ministerio de Asuntos Sociales - para potenciar una oferta asistencial de centros públicos que cubra a gran parte de la población española. La reforma que se caracteriza por una expansión acelerada de recursos explicaría la creación de una tipología nueva de servicios sociales que combina la creación de centros nuevos con centros que ya existían y que estaban en manos de instituciones privadas. Se asimilan los legados de instituciones e iniciativas asistenciales del pasado con el riesgo de heredar también sus limitaciones e ineficiencias. Pero el Plan Concertado es ante todo un proyecto de creación, más que de reconstrucción, aunque su rápida expansión no se explica sin comprender ese efecto "esponja" de instituciones que ya existen en el pasado. En poco tiempo el sistema cubre a casi la totalidad de la población, aunque las personas son sólo usuarios/as potenciales. El esfuerzo de la red asistencial es crear los centros nuevos que se necesiten, pero sobre todo impulsar una red pública, que se desmarque de la lógica de los servicios sociales benéficos desarrollados por la Iglesia durante el franquismo.

La red institucional comienza con la creación de un Ministerio central que, desde su posición, proyecta un programa de atención hacia la periferia en coordinación con el resto de Administraciones. Ese proceso se caracteriza por la interacción entre varios actores institucionales y corporativos en la creación de un modelo ideológico de atención. En los años ochenta los servicios sociales aún tienen poco protagonismo en los gastos generales del Estado con repercusión escasa en la población. A finales de los noventa los servicios sociales abarcan $60 \mathrm{mil} \mathrm{mi-}$ llones de pesetas; se destinan 50 millones de pesetas al año a cada centro.

El Plan Concertado atiende a personas en situaciones de emergencia y personas no cubiertas por otros planes de atención pública. Supone una de las piezas del engranaje del sistema de protección público que incluye diversos planes: el Plan de Igualdad de la Mujer, el Plan de Juventud, el Plan Gerontológico y el Sistema de Pensiones. Motivos diversos llevan a los gobernantes a realizar inversiones extraordinarias en un tipo de políticas sociales ${ }^{45}$. Por ejemplo, la precaria protección del nivel no contributivo de las pensiones en España -cuyo importe al mes en 1994 se reduce a las 32.635 pesetas - requiere de un sistema asistencial adecuado. El Plan Concertado supone pues la apuesta por el asistencialismo para compensar a los grupos marginales de la sociedad ${ }^{46}$.

La asistencialización crea innumerables incógnitas sobre la conceptualización de las iniciativas políticas de acción social. El sociólogo Gregorio RODRíGUEz CABRERO plantea que la década de los noventa supone en España la etapa de consolidación y crítica del sistema de servicios sociales, por parte de los/as expertos son conocedores de la limitada capacidad del. modelo para actuar frente a la extensión de la exclusión social en el Estado de Bienestar. (Rodríguez CaBrero, 1993). Por su parte, Manuel CASTEULS pone énfasis en la importancia de la participación popular y la autonomía local basada en cestrategias de negociación entre la sociedad civil y el sistema político a través de sus gobiemos locales. El incremento del poder de los gobiemos locales está en relación con la calidad de vida de las personas. La calidad de vida expresa la corriente reformista en políticas sociales. Sistemas de salud preventiva, centros comunitarios de atención a mujeres y niños/as deben ser gestionados por los gobiernos locales y en la medida de lo posible canalizados a través de la participación activa de la sociedad civil en la toma de decisiones.

La descentralización de recursos hacia las Comunidades Autónomas, por un lado, crea potencialmente un nuevo escenario de desigualdades sociales. El Plan Concertado de Prestaciones Básicas de Servicios Sociales en las Corporaciones Locales a partir de 1988 es quizás el cambio más importante que se produce en relación con el sector de servicios sociales en la historia española. Sin embargo, su estructura y actuación están poco evaluadas. Falta sobre todo un análisis de la capacidad de este Plan Concertado para reducir las desigualdad sociales en nuestro país. La conexión entre servicios sociales y redistribución de la desigualdad social es un tema complicado de establecer, para el que se requiere un análisis social más imaginativo. La variable a explicar es ese cambio en el proceso de configuración de la respuesta institucional para hacer frente a las necesidades y los problemas de la población. La expansión acelerada del Plan Concertado es el resultado de la reforma política de los servicios sociales iniciada a mediados de los ochenta. Una explicación posible sobre la institucionalización del Plan Concertado pone el énfasis en el desarrollo de asistencialización de las políticas de servicios sociales una vez se han consolidado las reformas de la educación y la sanidad. El Plan Concertado es un esfuerzo por poner en marcha un sistema de atención, bien a través de la creación de centros nuevos, bien a través de la asimilación de centros que ya existían en el pasado. La puesta en marcha del sistema no se consolida hasta dos años después de su inicio. Se considera 1990 como el año de referencia.

La evolución de los servicios sociales desde 1988 al final del siglo XX muestra el esfuerzo por redefinir un tipo de atención nuevo. Supone la apertura de una ventana política - policy window- caracterizada por la movilización considerable de recursos humanos y de infraestructuras materiales. Tras una década de funcionamiento se superan los casi mil centros con un personal de aproximadamente 15.000 trabajadores/as y en los que se atienden a casi tres millones de personas. Es una realidad lo suficientemente compleja para justificar el análisis por- 
menorizado del funcionamiento de los servicios sociales que junto a la sanidad y el sistema educativo constituye uno de los pilares básicos del modelo público español de Estado del Bienestar, al final del siglo XX.

Es necesario entender el desarrollo y alcance del Plan Concertado desde su implantación en 1988 hasta las previsiones del año 1996. El análisis de la estructura permite conocer la evolución de los equipamientos, el capital humano y los recursos económicos. El funcionamiento se puede medir a través de los indicadores sobre el alcance del sistema, el número de personas atendidas, el número de trabajadores/as, la población potencial que cubre y su extensión en el número de municipios. La Tabla
1 presenta la evolución desde 1988 hasta 1995 con las previsiones para 1996 según su estructura, el funcionamiento y los costes de la red de atención social. El análisis de la demanda atendida desde el inicio del sistema tiene el problema de cómo controlar el efecto de demanda inducida desde la oferta (supply induced demand $)^{47}$. El análisis de la demanda es un indicador indirecto de las necesidades de la población, pues es probable que en las zonas en las que se desarrolla más la oferta de centros y servicios sociales, las infraestructuras tienen un impacto mayor en la población. Hay que analizar el ritmo en el que se institucionaliza una red social para comprender el impacto de una política pública.

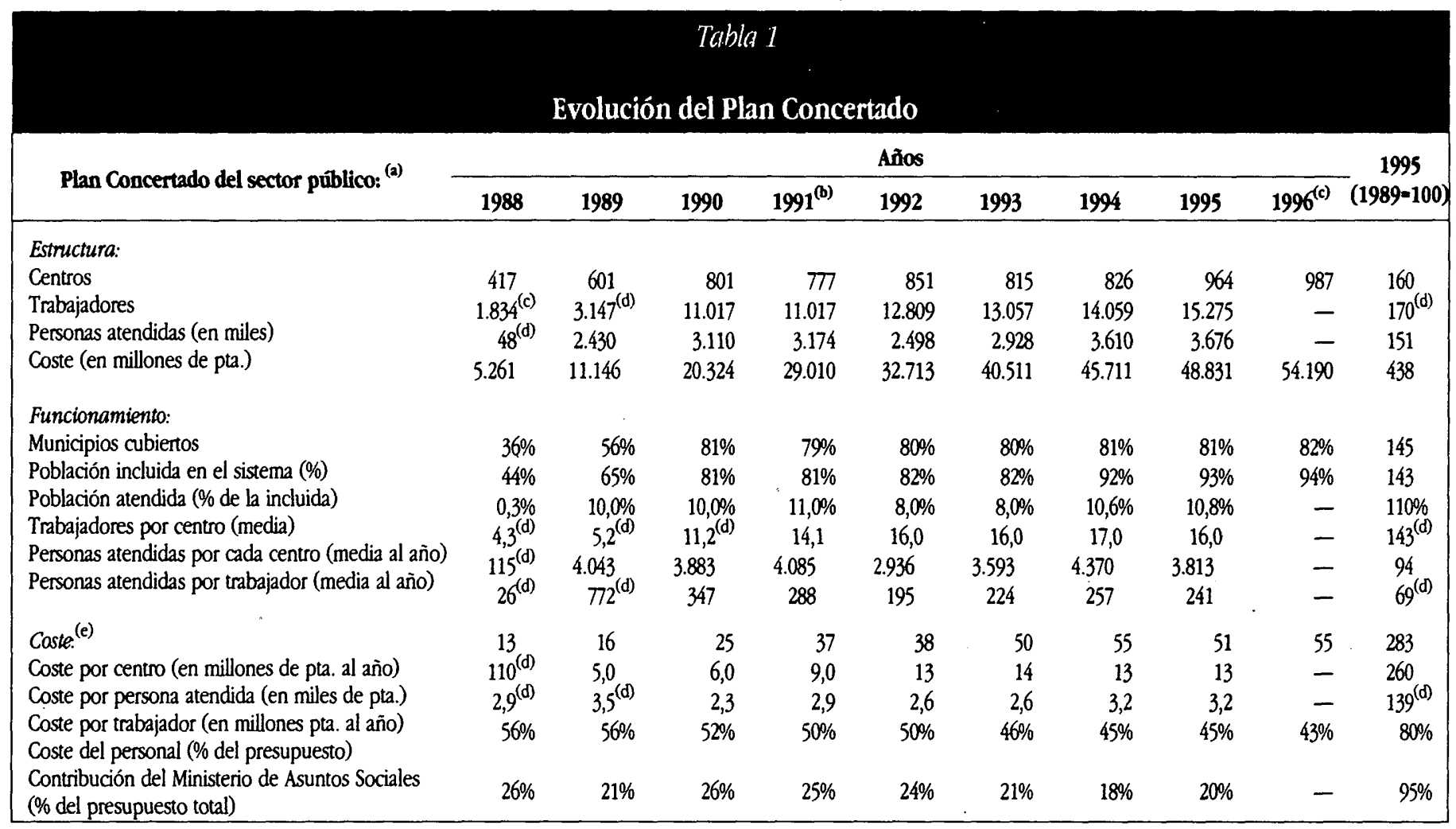

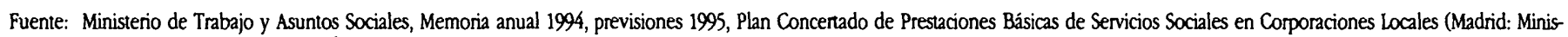
terio de Trabajo y Asuntos Sociales, 1996), pp. 173-190.

Notas: (a) Los datos suponen el crédito comprometido en los protocolos adicionales suscritos. El crédito real en 1995 es de 60 mil millones de pesetas.

(b) Desde el año 1991 la Comunidad Foral de Navarra no está incluida en el Plan Concertado.

(c) Los datos de 1996 son previsiones realizadas en 1995.

(d) Se utiliza el año 1990 como base $(=100)$ en vez de 1989, para calcular el incremento, ya que en 1988 y 1989 no se contabilizaron los/as trabajadores por prestaciones

(e) Los datos de 1988 no incluyen el número de servicios realizados de información.

(e) En pesetas corrientes.

El Plan Concertado comenzó en 1988 con 417 centros. Ocho años después alcanza casi el millar de centros en España. La distribución evolutiva de los recursos indica la velocidad a la que se produce el desarrollo de las infraestructuras que forman el Plan Concertado. En los dos primeros años, se dobla el número de centros que se incorporan a la red. A partir de $1990 \mathrm{el}$ número de centros es ya casi estable, aunque con un ligero aumento. Entre 1989 y 1995 (los dos años en que los datos son más fiables) se crean un $60 \%$ más de centros, para cubrir, el crecimiento de la nueva población incluida. El Plan Concertado empieza de forma acelerada para tender posteriormente a la estabilización si se pone en relación con la población realmente cubierta. Desde la implantación del Plan Concertado el número de trabajadores/as crece año tras año. A partir de 1992 el número de trabajadores/as aumenta lenta pero de forma continuada. En 1995 supera ya la cifra de los 15.000. Entre esos años se pro- 
duce un incremento del $70 \%$, algo superior al crecimiento en número de centros y de población. La política es pues expansionista en la contratación del personal. La tendencia global prioriza el aumento del número de trabajadores/as sociales frente al de los servicios sociales. Supone el monopolio profesional de una profesión nueva relacionada con la terciarización y mercantilización de la atención social.

El número de personas atendidas aumenta de forma similar a los centros. Casi desde el principio, el sistema atiende entre dos y cuatro millones de personas presentando oscilaciones, pero con una tendencia al aumento. Se produce un descenso "artificial" en los años 1991 y 1992 como resultado de la salida del sistema de la Comunidad Foral de Navarra. En 1994 se inicia una cierta recuperación. En la historia del sistema supone un incremento de un $51 \%$ en el número de personas atendidas en estos ocho años, es decir, un incremento ligeramente superior a la expansión del territorio, y la población incluida en el sistema. Pero es el coste la variable estructural que más incrementa. Mientras la estructura se extiende gradualmente 1,5 veces en esos ocho años, el coste global aumenta 4,3 veces respecto al año inicial. En 1988 el coste del sistema supera escasamente los 5.000 millones de pesetas, ocho años más tarde los presupuestos son casi diez veces más: unos 50.000 millones de pesetas. Llama la atención que el coste del sistema aumente tanto, cuando otras variables estructurales crecen de forma más gradual. Esa desproporción supone que la estructura es cada vez más cara, sin que por ello aumente el rendimiento del sistema. Se considera que el coste del sistema es uno de los problemas fundamentales del Plan Concertado.

El funcionamiento de los servicios del Plan Concertado alcanza el $81 \%$ de los municipios de las quince Comunidades Autónomas que están incluidas en el sistema (se excluye la Comunidad Foral de Navarra, País Vasco, Ceuta y Melilla). El crecimiento inicial se corresponde con el incremento de las variables estructurales. En la primera mitad de la década de los noventa se estabiliza el porcentaje de municipios incluidos. De nuevo el proceso describe un inicio acelerado para tender a la estabilización. Así, en 1995 se cubren 1,5 veces más municipios que en 1989. Esto coincide con el aumento estructural del sistema (aunque no con el coste) y fundamentalmente el de población. La expansión de la población incluida en el sistema sigue un proceso similar al descrito por los municipios. En los primeros años el Plan Concertado incluye a menos de la mitad de la población. Se inicia con un $44 \%$ de la población. El segundo año supone ya las dos terceras partes. La proporción se estabiliza en torno al 93\% de la población, en el año 1995. El incremento de la población es algo menor que el del número de municipios. Recientemente se incluyen municipios pequeños, con poca población. Pero la tendencia no parece que vaya a llegar al $100 \%$, al no poder incluir los municipios muy peque- ños. En realidad, la red a pesar de su crecimiento casi desde el año inicial atiende a un $11 \%$ de las personas que están incluidas en la red.

El Plan Concertado está formado por centros de tamaño medio. A medida que el sistema evoluciona se produce un incremento de trabajadores/as por centro ${ }^{48}$. En el año 1990 se superan los 11 trabajadores/as, aproximadamente la mitad de esos trabajadores tienen contratos temporales. El número máximo se alcanza en 1994 en que la media se sitúa en 17 trabajadores/as por cada centro de servicios sociales, al año siguiente desciende en número medio a 16 . El número de personas atendidas por cada centro apenas varía. El incremento durante siete años en el número de personas atendidas gira siempre en tomo a las cuatro mil personas por centro cada año, es decir, unas doce al día. La tendencia general se caracteriza por oscilaciones pequeñas. En ocho años de Plan Concertado decrece un $6 \%$ en el número de personas atendidas por cada centro. El sistema aumenta alrededor del $50 \%$, fundamentalmente porque cubre un $40 \%$ más de población en el mismo período. El 10\% restante supone aproximadamente la expansión de los servicios a la población. Realmente no se atiende a más personas porque el sistema sólo crece regularmente. Es un sistema estable salvo en el coste, que extrañamente se dispara (supone un $378 \%$ de incremento per capita). En el futuro no parece probable que la población atendida aumente mucho más. El sistema es pues estable desde su segundo año de funcionamiento. El aumento de los costes estructurales, el número de centros y el aumento del número de trabajadores/as no se corresponde con un número mayor de personas atendidas por centro. Se crean los centros que se necesitan; y se atiende solamente a un $6 \%$ más de la población prevista.

En 1990 se atiende a una media de 347 personas por trabajador/a, ocho años más tarde se atienden a 241. Este dato representa un 31\% menos de personas atendidas por trabajador/a. El año 1990 es el más productivo, mientras que 1992 es un año de estancamiento. A partir del año siguiente se inicia un período de recuperación que no alcanza la media de personas atendidas en 1989. Pese a esta tendencia, el sistema se expande para cubrir las necesidades de la población nueva que se anexiona al Plan Concertado. Sin embargo, la población atendida por trabajador/a disminuye más de lo previsto. Es decir, parece que cada vez el personal rinde menos. Quizás es que la asistencia se complica y se requieren más profesionales para cada caso.

La evolución de los costes de cada centro es un indicador excelente para evaluar el rendimiento del Plan Concertado. Al inicio del sistema, cada centro cuesta unos 13 millones de pesetas. En 1995 son unos 51 millones de pesetas por centro, con ligera disminución respecto al año anterior. La tendencia del Plan Concertado es al crecimiento constante en el coste por centro. 
Cada año supone más dinero que el año anterior hasta que en 1995 del crédito comprometido en los protocolos suscritos para cada centro desciende a 51 centros. En 1995 se destina un coste por centro 2,8 veces mayor que en 1989. Las personas atendidas en 1995 por cada centro suponen un decremento del 6\% de las que se atienden al principio del período. Se pasa de centros de 11 trabajadores/as con un coste de 25 millones de pesetas por centro, a centros de 16 trabajadores/as que cuestan $51 \mathrm{mi}$ llones. Es un incremento no sólo de la expansión sino del coste real por unidad (centro). El coste de las personas atendidas es una cantidad cada vez mayor debido, entre otras causas, al rendimiento tipo glass ceiling del funcionamiento del Plan Concertado. Tras el período de arranque, el coste por persona atendida se estabiliza en unas cinco mil pesetas. Luego se incrementa el coste 1,6 veces. Aun así, en 1995 se estabiliza el coste por persona en 13.000 pesetas. La variación supone un incremento real de 8.000 pesetas por persona respecto al año inicial. El dato se puede interpretar como un aspecto positivo del sistema aunque no se entiende bien el incremento global del coste del mismo (2,6 veces más al final del período) ${ }^{49}$.

$\mathrm{Al}$ inicio de la última década del siglo XX el Plan Concertado destina 2,3 millones de pesetas por cada trabajador/a. Cuatro años más tarde el coste se incrementa un $30 \%$. A excepción de los años 1991 y 1992 la progresión año tras año va en aumento pero sin suponer un incremento espectacular. El coste por trabajador/a incluye, además del salario, otros gastos relativos a los servicios realizados. En cualquier çaso, como la productividad real baja al $74 \%$, este incremento total del $39 \%$ es doblemente alto. Sin embargo, el coste del personal en los ocho años del Plan Concertado presenta una disminución que se produce de forma gradual. Se destina cada vez menos proporción del presupuesto al personal. En 1988 del total se destina a personal el $56 \%$. Tras siete años el porcentaje destinado es un 20\% menor. En 1994 se estabiliza en el $45 \%$ total de los costes. La tendencia muestra cómo se invierte más dinero del presupuesto en partidas de mantenimiento y los servicios realizados. Es decir, cada vez se paga más a trabajadores/as que atienden menos personas. Pero, aún así, todo el capítulo de personal (que es alrededor de la mitad del presupuesto) desciende relativamente.

El Ministerio de Trabajo y Asuntos Sociales (MiTAS) forma parte del Plan Concertado junto a las Corporaciones Locales, y las Comunidades Autónomas. Se prevé que a finales de milenio el Ministerio redefina su función en la red estatal de servicios sociales cediendo totalmente sus competencias a las administraciones autonómicas y locales, convirtiéndose en un organismo de mero control y coordinación. Se tiende al federalismo políti$\mathrm{co}$, en el que las administraciones autonómicas adquieren competencias fiscales para desarrollar sus reformas, $y$, de este modo, los propios usuarios realizan el control en la gestión a través de su capacidad de voto. Desde el inicio del Plan Concertado hasta 1992 el Ministerio de Asuntos Sociales se encarga aproximadamente de una cuarta parte del coste total. Con el gobierno del Partido Popular el Ministerio de Asuntos Sociales se adjunta al Ministerio de Trabajo, acentuándose así ese papel colateral del Ministerio central en la red general. La evolución en la reforma es que el Ministerio central tienda a ceder protagonismo a la Administración autonómica y a las. Corporaciones Locales. Se observa que en los últimos años del Plan Concertado, son las Corporaciones Locales y las Comunidades Autónomas las que llevan más el peso del sistema, repartiéndose más del $70 \%$ de la carga económica. El MiTAS aporta tres veces más dinero en números absolutos que en 1989, aunque ese dinero significa un porcentaje menor en números relativos.

El coste del sistema y la aparente disminución en la productividad de los/as trabajadores se presentan como un problema. El Plan Concertado en los primeros ocho años crece porque aumenta la población incluida en el sistema; concretamente en un $40 \%$. Además, atiende a un $6 \%$ adicional de población, por encima de ese $40 \%$ de crecimiento de población incluida en el sistema. Por eso casi todos los indicadores crecen alrededor del 50\% en ocho años. El coste (en pesetas corrientes) se cuadriplica, y aunque cada vez hay más trabajadores/as (incluso más de los previstos por la expansión territorial o la población incluida en el sistema) el capítulo de personal de los presupuestos no aumenta relativamente. Lo esperable es que la población realmente atendida fuese mayor. Pero la realidad es que el incremento del personal no se ve reflejado en un aumento de los servicios, más bien lo contrario.

El tamaño medio de los centros, formados por 17 trabajadores de media, que atiende a casi cuatro millones de personas al año, demuestra que la productividad real es escasa -sobre todo si el $60 \%$ de los servicios son de orientación, servicio que no requiere de gran especialización. La organización sigue una pauta contradictoria de informar más que atender. Se explica así la pérdida de protagonismo de los Albergues, los Centros de Acogida y las Unidades de Trabajo Social (que son los centros más pequeños de atención personalizada) y se da paso a los centros de servicios sociales más complejos -Equipamientos Integrados y Estructuras Intermedias - en los que se ofrecen principalmente servicios más específicos. El cambio cualitativo se aprecia en la propia naturaleza de los centros. La tecnificación explicaría que las personas atendidas reciban asistencia más profesional y la acción no se reduzca a la mera internalización en Centros de Acogida y Albergues. Se priman, así, los centros más dinámicos y con mayor oferta que realizan atención más específica, en las casas o aportando ayudas económicas para situaciones de emergencia. Los servicios sociales se alejan ideológicamente del modelo internalista de los Centros de Acogida, 
aun así se modemizan los Albergues que suplantan el protagonismo de los Centros de Acogida que cada vez tienen un peso menor en el sistema. Es interesante observar las reacciones tipo rmuelle. que sugiere que el sistema es sobre todo un mecanismo de compensación entre los diferentes centros de atención.

El éxito de una expansión rápida garantiza el acceso a los servicios a una proporción considerable de personas. Pero la verdadera efectividad y eficiencia de una organización que presenta, ya desde su inicio, un incremento significativo en los costes se mide con la calidad de la atención, la preparación de los trabajadores y lo adecuado de los centros disponibles. El análisis evolutivo demuestra que la expansión estructural es prioritaria por delante de la calidad real de los servicios que se ofrecen. En un principio, el objetivo principal es la expansión con un énfasis especial en hacer accesible una red de centros y servicios que supongan los estándares mínimos para toda la población. En la década de los noventa se consolida así la red de infraestruc- turas necesarias para atender a personas en situación de emergencia, aunque surgen incógnitas sobre su verdadera efectividad. La red sigue atendiendo sobre todo a personas y a grupos tradicionalmente marginados por la sociedad, los excluidos sociales. El funcionamiento de esta red es un banco de pruebas para analizar los esfuerzos del Estado, permite comprender mejor los problemas sociales y la desigualdad generadas por la sociedad de finales del siglo XX. Existe, pues, un balance desigual entre la estructura que se expande, sobre todo en los recursos disponibles, y el funcionamiento que se estabiliza a los pocos años. Se explica asi el desarrollo de una política pública en la que la profesionalización y la tecnificación, factores propios de un abuen servicio, coexisten con un proceso acentuado de burocratización que se considera un factor negativo. Mientras que año tras año el coste se dispara a medida que se institucionaliza el sistema, el rendimiento en el número de personas atendidas por trabajador decrece. Se explica así cierta saturación en los límites del sistema que parece que no va a crecer mucho más en el futuro.

\footnotetext{
- Vicepresidente COST European Corporation in the Field of Scientific and Technical Research, Ciencias Sociales, Comisión Europea, Bruselas. Director del Departamento de Sociología de la Universidad de Barcelona.

- Department of Sociology, University of Illinois.

** Agradecemos las críticas y comentarios de Jordi Cais, Sonia Frías, Francisco J. Granados, Marga Marí Klose, Raül Tornos y Elisabeth Vaquera. Algunas ideas excelentes proceden de Demetrio Casado. Para más información se puede contactar por correo electrónico a:demiguel@eco.ub.es.
}

' El término fue ya utilizado por Émile DuRKHEIM hace un siglo en su estudio sobre El Suicidio (1897)

- Se traduce por subclase o por infraclase pero se refiere a personas fuera del sistema de estratificación, desgajadas, excluidas del sistema social.

3 Servicios sociales. es un concepto mal definido y que cambia constantemente. En los informes sociológicos globales es el único que define al principio su propio objeto, pues no hay unanimidad sobre su extensión ni temática. Se refiere a un sector marginal y marginado dentro de la sociedad, en que ni siquiera su objeto de estudio es legítimo, o por lo menos no está claro.

' Es un área llena de un argot especial, que produce un sinfín de discusiones profesionales. Los conceptos suelen ser poco claros, como: colectivos vulnerables, cooperación social, trabajo comunitario, investigación participativa, reinserción social, ayuda a domicilio, voluntariado, etc.

'A menudo se utiliza la terminología de red integral. aunque no se especifica casi nunca qué integra. Es una palabra que está de moda a finales del siglo XX.

- Esa combinación en una red única socio-sanitaria es difícil, pues supone conflictos de poder considerables. La estructura del sector sanitario -dominada fundamentalmente por la profesión médica - tiene una envergadura importante y unas estructuras de poder y de decisión ya institucionalizadas. La incorporación de servicios sociales como una estructura subordinada es lo que incomoda y no añade mucho más poder ni recursos a la sanidad. A su vez, las profesiones dominantes en servicios sociales (sobre todo Trabajo Social) no pueden ni quiere competir con la profesión médica y las otras profesiones sanitarias de gran tradición y status (farmacia, odontologia, investigación médica, incluso enfermeria). Es pues poco probable que se logre esa unión, aunque desde el punto de vista de la clientela - toda la población- podría ser beneficiosa.

' El término -marginación. es interesante en castellano, pues sugiere personas que están al margen de la sociedad, es decir, fuera de ella. También puede utilizarse como personas que viven en los márgenes o bordes de la sociedad, al filo de esa frontera entre la estructura social y la nada, la exclusión social, o incluso la auto-exclusión social (suicidio, muerte por drogodependencias, etc.). Marginación social no tiene una buena traducción al inglés, por lo que no se incorpora del inglés, tendiéndose actualmente a exclusión social. como concepto favorito.

${ }^{8}$ Esta ayuda a veces se realiza selectivamente, y siempre que conforme con pautas religiosas católicas, con sus ideologías, e incluso con su clientela.

$?$ Con cargo, por ejemplo, a la partida de -Otros fines sociales. del IRPF.

ii La mayoría son mujeres. Este voluntariado está formado a veces por personas beneficiarias de los propios servicios sociales. Lo mismo sucede en otras ONG.

$"$ MiTAS o Ministerio de Trabajo y Asuntos Sociales. La terminología de asuntos sociales es más indefinida aún, pues incluye no sólo los servicios sociales sino una serie más extensa de actuaciones y servicios de carácter benéfico. Con la descentralización a las Comunidades Autónomas asume también una función de coordinación, planificación y de financiación de programas.

12. El proceso de descentralización territorial en el que las $C C$ AA lComunidades Autónomasl tienen el verdadero poder frente a los Ayuntamientos dada la debilidad financiera de estos últimos (denominados correctamente como procesos de recentralización en las $\mathrm{CC}$ AA de las competencias en stencia social). (RodRiguEz CABRERO, 1996: 366).

${ }_{13}$ En ese sector la mujer pasa del $46 \%$ al $55 \%$. Los datos exactos pueden verse en el estudio de Rodríguez CABRERO (1996).

" Datos más detallados se pueden ver en Rodríguez Cabrero (1996).

15 En nuestra opinión, la sobre-utilización del término -modelo y sistema. suele ser equívoco. No existe un modelo de servicios sociales, como no lo hay de sanidad, ni policía. Suele ser una expresión utilizada con ligereza.

16 Quinto informe sociológico sobre la situación social en España: Sociedad para todos en el año 2000 (Madrid: Fundación Foessa y Cáritas Española, 1994), p. 1.857. A lo largo del presente articulo citamos el Quinto Informe Foessa abreviadamente como F5. 
F5, p. 1.867

is El Plan CCB en 1965 parte precisamente de esa idea fundamental de acción social- pero curiosamente no presenta luego una estructura de servicios sociales, sino de problemas y necesidades de la población. Parece que podemos considerar al Plan CCB como el primer informe sobre la situación social de España. Pues bien, en la estructura temática de la citada obra no aparece el concepto de acción social o de servicios sociales, ni equivalente; esto resulta especialmente significativo teniendo en cuenta que aquélla se subtitula Plan de Promoción Social, Asistencia Social y Beneficencia de la Iglesia en España. (F5, p. 1.740). Se basa en la definición de seis problemas/necesidades, en realidad de seis áreas sociales: alimentación, sanidad, educación (instrucción.), vivienda, trabajo y comunidad social. Pero como se señala no hay una visión global o estructural de los seis problemas/necesidades. Incluso la terminologia de problemas/necesidad es lógicamente la inversa: necesidades/problemas.

19 F5, p. 1.745 .

" En el lado republicano se denomina Socorro Rojo.

$\because$ Un tipo de las críticas que esta desigualdad genera: •A finales del pasado decenio lla década de los ochental se produjo un debate sobre el 'ingreso minimo de inserción'; en el mismo las Comunidades Autónomas ricas parecieron más favorables que las pobres a la nueva institución. ¿No será porque, teniendo más pobres, cuentan con menos recursos? ¿No hubiera sido distinta la reacción en el caso de que el Estado tuviera facultades para la compensación territorial en esta materia? En el orden formal nos preguntamos si no hubiera sido prudente y piadoso que la Constitución hubiese encomendado expresamente al Estado la tarea de jubilar dignamente a la venerable y maltrecha Beneficencia. Y iquién responde de los compromisos internacionales (tratados, convenciones, etc.) que adquiere nuestro Estado en materia de servicios sociales? (F5, p. 1.751).

:2 IL critica al centralismo llegó a los servicios sociales como una expresión más del antifranquismo [...] pero también por el eclipse de la provincia a que aludiamos anteriormente, se propugnó el municipalismo para la acción social [....] Mediante la Constitución y los Estatutos de Autonomía se ha producido una auténtica descentralización de los servicios sociales a las Comunidades Autónomas [....] sustitución del centralismo estatal por la recentralización en las Comunidades Autónomas. (F5, p. 1. 759).

-3itado en F5, p. 1.765. La utilización del concepto de •riesgo• es un anglicismo que no se suele definir operativamente.

-Se trata de una plantilla con un alto grado de precariedad. Podemos suponer que esta circunstancia se relaciona muy estrechamente con el régimen de subvenciones anuales sobre el que viene montándose el desarrollo de los servicios del nivel primario. Tales subvenciones provenían inicialmente de las Comunidades Autónomas sólo; ahora de la Administración Central también; en ambos supuestos las Corporaciones Locales no se arriesgan a garantizar el empleo más allá de cada ejercicio. es decir, de cada presupuesto anual. (F5, p. 1,768).

- Citado en el F5, p. 1.788.

* El período dominado por el intervencionismo de los organismos oficiales. se refiere al Gobierno del PSOE. F5, p. 1.789.

Entre ellos/as hay un $0,3 \%$ de apátridas. Los datos exactos se pueden ver en la Tabla 11.25 del F5, p. 1.791. Se señala que estos datos no incluyen a las personas menores de edad, dependientes de residentes adultos/as. Es importante señalar que estas estadísticas oficiales (del INE) no incluyen a los extranjeros ilegales, cuya cantidad es numerosa, aunque dificil de calcular.

* Cada vez se emplea más la expresión .población diana. que es una traducción de target population. La mejor traducción sería población objeto, pero tiene otras connotaciones en castellano. Por otro lado, preferimos la expresión personas con minusvalia. que no -minusválidos.

* Según la Encuesta sobre discapacidades, deficiencias y minusualias (INE 1987) la población con discapacidades de *ver. son el $2,13 \%$ del total, es decir, 817.432 personas. Sin embargo, la ONCE no cubre a toda esa población. Para un análisis detallado de la encuesta, y una aplicación al caso de Barcelona puede verse el libro de Colla. DO, DOMinguez, y de MiGuel (1992). Véase también el informe del INE publicado dos años después que la encuesta Las discapacidades de la población española (INE 1989).
"En 1993 tienen 187 centros, y más de 13.000 personas atendidas.

"Son 40.061 casos contabilizados al 30 de junio de 1996 , desde 1981. Incluye casos vivos y muertos.

3. F5, p. 1.806

" IMI o programas de ingreso mínimo de inserción, y RMI renta mínima de inserción. Se utilizan ambas terminologías.

: Pero curiosamente todos los cálculos sobre el Plan Concertado se realizan sobre población total, cuando esto es inexacto. Debería de hacerse por población necesitada, o quizás población potencialmente necesitada. Lo que pasa es que esa base es difícil de estimar.

35 Esta cantidad incluye el Plan Concertado, Inserso, Plan Gerontológico y guarderías infantiles entre las instituciones principales.

3. Aqui el Informe Foessa señala que -podemos apreciar una cierta asociación estadística de la mayor frecuencia de los cuidados familiares a la religiosidad, entre los católicos. (F5, p. 1.830). Sin embargo, los datos de la Tabla 11.55 demuestran que las personas más cuidadoras son las agnósticas, cuidando sobre todo a hijos/as y enfermos/as. No tanto a abuelos/as. El problema es que hay una asociación estrecha entre religiosidad y edad de las personas, que invalida los datos de religiosidad si no se controla por edad.

5 F5, p. 1.831 .

ss Son inexactos por dos razones: Primera, porque la clase muy baja, y sobre todo marginal, no se suele entrevistar; incluso a menudo no entra en la muestra por no tener un hogar fijo, o estar institucionalizada. Segunda, son realidades pequeñas, que afectan a pocas personas. Se necesitan muestras grandes, para luego entrevistar más en profundidad a las personas afectadas. Ésta es la estrategia de la encuesta de dedimi del INE de 1987. Pero las encuestas generales a la población suelen ser a mayores de edad (18 años y más) y no muy extensas.

3. Los datos aparecen en la Tabla 11.58, del F5, p. 1.833. Nosotros nos inclinamos por la hipótesis de que estos datos no son fiables.

ii $\mathrm{F} 5$, pp. 1.833-1.835.

"Hay una cierta relación entre religiosidad católica y voluntariado, especialmente en el tema de contribución económica. Pero hay que tener en cuenta que la religiosidad católica está asociada en España con edad y con ser mujer. Habría que controlar por esas variables para establecer una relación concluyente. Ver los datos en la Tabla $11.60, \mathrm{~F} 5$, p. 1.837

12. Algunas de estas organizaciones -como la Cruz Roja - generan escándalos financieros de envergadura durante los años ochenta y noventa.

13. En tales supuestos la hipotética función fomentadora de las subvenciones se transforma, a nuestro parecer, en una cripto-contratación exterma. En efecto, las Administraciones Públicas practican por este medio la gestión o provisión indirecta de servicios. Nos refuerza este parecer un hecho administrativo que acaece en el período de nuestro interés: el arbitrio del convenio-programa, que algunas organizaciones subvencionadoras han adoptado. Se trata de un instrumento que recuerda intensamente al concierto contrato de servicios, salvo que se aplica mediante una relación de adhesión. ( $F 5$, p. 1.839, cursivas añadidas). El comentario insinúa más que afirma, pero presenta pistas para seguir investigando.

"F5, p. 1.840 .

El tipo de mandato político, o las reacciones legislativas de los/as gobemantes en situaciones de crisis, pueden ser factores explicativos de la puesta en marcha de programas e iniciativas reguladoras. (KFELER, 1993: 45).

15. MOTA, 1996: 289-319.

- Para un análisis detallado del problema de la demanda inducida desde la oferta, véase la explicación de ese problema aplicado al análisis del criterio de necesidad como garantía de equidad territorial en Ana Rico, 1998: p. 556-557.

"En los años 1988 y 1989 no se superan los seis trabajadores/as de media por cada centro. Pero hay que tener en cuenta que en esos años no se contabilizan los servicios que realizan los/as trabajadores con contratos temporales.

19. Al ser pesetas corrientes, una parte se debe a la inflación. 


\section{Bibliografia}

AHMAD, Ehtisham et al, Financing Decentralized Expeditures, (Washington DC: Edward Elgar, 1997), 396 pp.

Ajuntament de Barcelona, Barcelona societat/6. Revista d'informació $i$ estudis socials (Barcelona: Gerència del Sector de Serveis Personals, 1996), 135 pp.

Álvarez-MRANDA, Berta et al., Dilemas del Estado de Bienestar. (Madrid: Fundación Argentaria, 1996), $439 \mathrm{pp}$.

AZnar, Manuel y CASADO Demetrio, Perspectivas de la Seguridad Social española, (Madrid: Acebo, 1988).

BANDRES, Eduardo et al., Las políticas redistributivas (Madrid: Fundación Argentaria, 1996), 426 pp. (RODRÍGUEZ CABRERO 1996): LLos servicios sociales en España: Implantación, generación de empleo y evaluación de su efectividad.

BAzo, María Teresa, La ancianidad del futuro (Barcelona: SG editores, 1992), 326 pp.

Brint, Steven, In Age of Experts: the Changing Role of Professionals in Politics and Public Life (New Jersey: Princeton University Press, 1994), 274 pp.

Borx, Carles, Partidos políticos, crecimiento e igualdad. Estrategias económicas conservadoras y socialdemócratas en la economia mundial (Madrid: Alianza, 1996), 407 pp.

CAIIS, Jordi, Metodologia del análisis comparativo (Madrid: Centro de Investigaciones Sociológicas, 1997), $201 \mathrm{pp}$.

CAMPo, Salustiano del et al., Tendencias sociales en España 1960-1990 (Bilbao: Fundación BBV, 1993), 3 vols., 585, 607, y 559 pp. (un total de 1.751 pp.).

Cáritas Española, Plan CCB: Plan de promoción social, asistencia social y beneficencia de la Iglesia en España (Madrid: Euramérica, 1965), 3 volúmenes, con un total de 1.174 pp: vol 1, 452 pp.; vol. 2, 429 pp.; y vol 3, 293 pp.

CASADO, Demetrio, Fundación Foessa: Tres estudios para un sistema de indicadores sociales, Revista de Estudios Agro-Sociales 63 (1968): 159-168.

CASADO, Demetrio et al., ‘Acción social y servicios sociales, pp. 1.735-1.880, en Fundación Foessa, ed. Quinto informe sociológico sobre la situación social en España (Madrid: Fundación Foessa, 1994), 2 vols., 2.313 pp.

CASAL, Joaquim et al., Sintesis actualizada del III informe Foessa 1978 (Madrid: Euramérica, 1978), 732.pp.

CASTELS, Manuel, La era de la información (Madrid: Alianza, 1997), 495 pp.

Centro Estatal de Documentación e Información sobre Servicios Sociales, Guia de recursos sociales para el ciudadano, (Madrid, 1985).

Consejo Económico y Social (CES), Memoria sobre la situación socioeconómica y laboral de España en 1995 (Madrid: Consejo Económico y Social, 1996), 547 pp.

Consejo General de Colegios Oficiales de Diplomados en Trabajo Social y Asistentes Sociales, Seguimiento de la gestión de los servicios sociales comunitarios, propuesta de un sistema de indicadores (Madrid: Siglo XXI, 1988), 142 pp.

Corona Ramón, Juan, y Pedro PUY FraGA, Federalismo competitivo y financiación autonómica, Jomadas de Economía Publica, Valencia, Febrero 1998.

Ditez NiColÁs, Juan, La realidad social en España octubre 1991 - junio 1992 (Barcelona: BBV, BBK, Caja de Madrid, y Ediciones B, 1993).

Díz NiColás, Juan, La realidad social en España octubre 1992 - junio 1993 (Barcelona: BBV, BBK, Caja de Madrid, y Ediciones B, 1994), 946 pp.

DíEŻ NiColás, Juan, La realidad social en España octubre 1993 - junio 1994 (Barcelona: BBV, BBK, Caja de Madrid, 1995), 1.042 pp.
Dízz Nicolís, Juan, y Jesús M. de Miguel, Control de natalidad en EspañałBarcelona: Fontanella, 1981), $366 \mathrm{pp}$.

DíEZ Nicolis, Juan, Los españoles y la opinión priblica (Madrid: Editora Nacional, 1975) $261 \mathrm{pp}$.

Donahue D., John, La decisión de privatizar. Fines priblicas y medios privados (Barcelona: Paidós, 1991).

Douglas Ashford, D. La aparición de los Estados del Bienestar (Madrid: Ministerio de Trabajo y Seguridad Social, 1991).

EsCOBAR, Modesto, •Desviación, desigualdad, polarización: Medidas de la diversidad social. Revista Española de Investigaciones Sociológicas 82 (1998)

FERNÁNDEZ GOMEZ, Natividad, La financiación de las Comunidades Autónomas: Una propuesta de corresponsabilidad fiscal (Madrid: Instituto de Estudios Económicos, 1993), $385 \mathrm{pp}$

Fundación Foessa, Suplemento al informe sociológico sobre la situación social de España 1970 (Madrid: Euramérica, 1971-1974).

Fundación Foessa, Estudios sociológicos sobre la situación social de España 1975 (Madrid: Euramérica, 1976), 1403 pp.

Fundación Foessa, Informe sociológico sobre la situación social de España (Madrid: Euramérica, 1966), 361 pp.

Fundación Foessa, Informe sociológico sobre la situación social de España 1970 (Madrid: Euramérica, 1970), $1634 \mathrm{pp}$.

Fundación Foessa, Informe sociológico sobre el cambio politico en España 1975-1981 (Madrid: Euramérica, 1981), vol. 1, 658 pp

Fundación Foessa, Informe sociológico sobre el cambio social en España 1975-1983 (Madrid: Euramérica, 1983), vol. 2, 976 pp.

Fundación Foessa, Quinto informe sociológico sobre la situación social de España 1983-1993: La sociedad para todos en el año 2000 (Madrid: Fundación Foessa, 1994), 2 vols., $2.313 \mathrm{pp}$

GarCía Cotarelo, Ramón, Del Estado del Bienestar al Estado del Malestar (Madrid: Centros de Estudios Constitucionales, 1986).

Garća Viso, Manuel, Diagnóstico y valoración de discapacidades (Madrid: Real Patronato de Prevención y de Atención a Personas con Minusvalía, 1990), 141 pp.

GaRVÍA SOTO, Roberto La onganización nacional de ciegos: Un estudio institucional (Madrid: Peninsular, 1993), 289 pp.

Gonź́lez BLAsCo, Pedro (ed.), Sintesis del quinto informe sociológico sobre la situación social en España: Sociedad para todos en el año 2000 (Madrid: Documentación Social: Revista de Estudios Sociales y de Sociología Aplicada, 1995), 546 pp.

GosTA EspiNG, Andersen, Los tres mundos del Estado del Bienestar (Valencia: Alfons el Magnanim, 1993).

GUTIERREZ RESA, Antonio, Cánitaș Española en la Saciedad del Bienestar 1942-(Barcelona: Hacer, 1993)

IGLESIAS DE Ussel, Julio, Guia de los servicios sociales de la Iglesia en Andalucia (Córdoba: Publicaciones Caja Sur, 1995), 649 pp

IGLESLAS DE USSE, Julio, Informe sociológico sobre los senvicios sociales de la Iglesia de Andalucia (Córdoba: Publicaciones Obra Social y Cultural Caja Sur, 1996), 287 pp 
Instituto Nacional de Servicios Sociales La tercera edad en España: Aspectos cuantitativos (Madrid: Ministerio de Asuntos Sociales, 1989) 210 pp.

Instituto Nacional de Servicios Sociales La tercera edad en Eumpa: Necesidades y demandas (Madrid: Ministerio de Asuntos Sociales, 1989) 399 pp.

Instituto Nacional de Servicios Sociales La tercera edad en Esparia: Necesidades y demandas (Madrid: Ministerio de Asuntos Sociales, 1989) 211 pp.

Instituto Nacional de Servicios Sociales, Memoria de actividad sobre el INSERSO (Madrid: Instituto Nacional sobre Servicios Sociales, 1991).

Instituto Nacional de Estadística, Panorámica social de España (Madrid: Instituto Nacional de Estadistica, 1994), $841 \mathrm{pp}$.

IRIGOYEN, Juan La crisis del sistema sanitario en España: Una interpretación sociológica (Granada: Biblioteca de Ciencias Políicas y Sociología, 1995), 294 pp.

Miguel, Amando de, et al., La sociedad española 1992-93: Informe sociológico de la Universidad Complutense (Madrid: Alianza Editorial, 1992), 826 pp.

Miguel, Amando de, et al., La sociedad española 1993-94: Informe sociológico de la Universidad Complutense (Madrid: Alianza Editorial, 1994), 1.063 pp., y cuestionarios.

Miguel, Amando de, et al., La sociedad española 1994-95: Informe sociológico de la Universidad Complutense (Madrid: Editorial Complutense SA, 1995), 865 pp., y cuestionarios.

MIGUEL, Amando de, et al., Sintesis del informe sociológico sobre la situación social de España 1970 (Madrid: Euramérica, 1972), 348 pp.

MIGuEl, Amando de, et al., Capitulo 5: Vida política y asociativa (Madrid: Euramérica, 1970), $61 \mathrm{pp}$, fotocopiado.

MIGUEl DE M., Jesús Estructura y cambio social en España (Madrid: Alianza, 1998), 681 pp.

Miguel DE M., Jesús y Juan Díz Nicolás Políticas de población (Madrid: Espasa-Calpe, 1985), $301 \mathrm{pp}$.

MIGUEL DE M., Jesús Estructura de la prevención de deficiencias: El caso de Barcelona(Madrid: Real Patronato de Prevención y de Atención a Personas con Minusvalia, 1991), $500 \mathrm{pp}$.
Ministerio de Asuntos Sociales, Manual de cumplimentación del sistema de información de usuarios de servicios sociales: Ficha Social, SIUSS (Madrid: Ministerio de Asuntos Sociales, 1993), $95 \mathrm{pp}$.

Ministerio de Asuntos Sociales, Primeras Jornadas Nacionales de Servicios Sociales Co munitarios (Madrid: Ministerio de Asuntos Sociales, 1995), 180 pp.

Mogín Barquín, M. Teresa. EEl Plan Concertado de Prestaciones Básicas de Servicios Sociales en las Corporaciones Locales, pp. 123-124 en Ministerio de Asuntos Sociales, Primeras Jomadas Nacionales de Servicios Sociales Comunitarios (Madrid: Ministerio de Asuntos Sociales, 1995), $180 \mathrm{pp}$.

PIERSON, Paul, Dismantling the Welfare State? Reagan, Thatcher, and the Politics of Retrenchment (Cambridge: Cambridge University Press, 1994), 213 pp.

PutNam, D. Robert Making Democracy Work (New Yersey: Princeton University Press, 1993), $256 \mathrm{pp}$

REY DEL CASTLLO, J. Descentralización de los servicios sanitarios: Aspectos generales y análisis del caso español (Granada: Escuela Andaluza de Salud Pública, 1998), 445 pp.

RICO GÓMEZ, Ana, Descentralización y reforma sanitaria en España (1976-1996): In tensidad de preferencias y autonomia politica como condiciones para el buen gobierno (Madrid: Centro de Estudios Avanzados en Ciencias Sociales, 1998) 730 pp.

RoDRiGuEZ, Josep A., EEl reparto del bienestar: Salud y desigualdad social en España. Sistema 83 (1988), pp. 75-112.

RodrígueZ, Josep A., The Politics of Medicine in Spain (New Haven, Conn.: Yale University, tesis doctoral, 1990).

RodriGuez, Josep A., Envejecimiento y familia (Madrid: Centro de Investigaciones Sociológicas, 1994), $115 \mathrm{pp}$.

Rodriguez CaBrero, Gregorio, servicios sociales en España: Implantación, generación de empleo y evaluación de su efectividad, pp. 361-423, en Eduardo BANDRés y otros, Las politicas redistributivas (Madrid: Fundación Argentaria, 1996), 426 pp.

RODRíguez CABRERo, Gregorio, La evolución de los senvicios sociales (Madrid: Inserso, 1987)

SEBASTIÁN, Luis de, Mundo rico, mundo pobre (Madrid: Sal Terrae, 1992). 